\title{
Nanoporous Gold Electrodes and Their Applications in Analytical Chemistry
}

\author{
Maryanne M. Collinson \\ Department of Chemistry, Virginia Commonwealth University, 1001 West Main Street, Richmond, VA 23284-2006, USA \\ Correspondence should be addressed to Maryanne M. Collinson; mmcollinson@vcu.edu
}

Received 9 December 2012; Accepted 26 December 2012

Academic Editors: N. Chaniotakis, D. Kara, V. A. Lemos, E. Lodyga-Chruscinska, and B. Rittich

Copyright ( 2013 Maryanne M. Collinson. This is an open access article distributed under the Creative Commons Attribution License, which permits unrestricted use, distribution, and reproduction in any medium, provided the original work is properly cited.

\begin{abstract}
Nanoporous gold prepared by dealloying Au:Ag alloys has recently become an attractive material in the field of analytical chemistry. This conductive material has an open, 3D porous framework consisting of nanosized pores and ligaments with surface areas that are 10 s to 100 s of times larger than planar gold of an equivalent geometric area. The high surface area coupled with an open pore network makes nanoporous gold an ideal support for the development of chemical sensors. Important attributes include conductivity, high surface area, ease of preparation and modification, tunable pore size, and a bicontinuous open pore network. In this paper, the fabrication, characterization, and applications of nanoporous gold in chemical sensing are reviewed specifically as they relate to the development of immunosensors, enzyme-based biosensors, DNA sensors, Raman sensors, and small molecule sensors.
\end{abstract}

\section{Introduction}

High surface area nanostructured electrodes have received considerable attention in recent years [1-18]. These materials are conductive, have surface areas that are typically 2-1000 times larger than a planar electrode of similar size, and consist of either oriented, well-defined or random pore morphology. Such high surface areas are important to a number of applications, particularly those in the field of chemical sensing when the goal is to improve sensitivity and lower detection limits. In electroanalytical chemistry, for example, the increased surface area can lead to a greater amount of an immobilized reagent on the surface. This can potentially lead to larger currents, even for diffusing species, because Faradaic current typically scales linearly with electrode area; a significantly larger electrode area can potentially yield better $\mathrm{S} / \mathrm{N}$ ratios, enhanced sensitivity, and lower detection limits. High surface area noble metal electrodes have been fabricated using a number of different approaches including hard templating of latex spheres or $\mathrm{SiO}_{2}$ spheres $[7,8,19,20]$, chemical dealloying $[9,21]$, electrochemical dealloying [22, 23], $\mathrm{H}_{2}$ bubble formation [24], electrodeposition in the pores of nanopore membranes $[1,2]$ as well as from ensembles of gold nanoparticles $[5,6]$, gold microparticles $[25,26]$, and electrospun gold nanofibers [3, 4]. Each approach has its unique advantages and disadvantages. Figure 1 shows simple examples of different types of high surface area, nanostructured electrodes.

The focus of this paper is on nanoporous gold electrodes, particularly those formed via dealloying an Au:Ag alloy, and their application to the field of analytical chemistry, specifically chemical sensing. The reader is referred to other reviews for more information related to the material, engineering and mechanical aspects of nanoporous gold [15, $27,28]$, electroanalysis with macroporous electrodes [16, 29], energy applications of nanostructured electrodes [30], electrochemical analysis at nanoporous electrodes [14], and electrocatalysis with nanoporous materials [13]. A book on nanoporous gold by Wittstock et al. has also recently been published [31]. This paper will begin with a description of nanoporous gold, followed by a discussion on fabrication and characterization [9], its features and unique attributes, and then end with applications in the field of chemical sensing. This paper is not meant to be inclusive of all papers on this subject but rather is designed to give the reader an overview of the subject, particularly as it pertains to analytical chemistry with a focus on studies published during the past five years. 


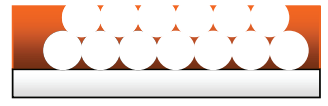

Macroporous gold electrode prepared from monodisperse latex spheres. Pore diameters: $\sim 100-5000 \mathrm{~nm}[8]$.

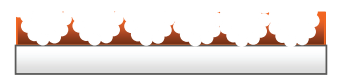

Hierarchical gold electrode prepared from hierarchical polystyrene latex spheres. Pore diameters: $\sim 20 \mathrm{~nm}-5000 \mathrm{~nm}$ [7].

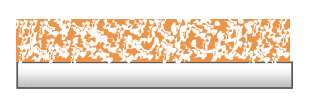

Nanoporous gold electrode prepared by selective dealloying a $\mathrm{Au}$ : Ag alloy. Pore sizes $\sim 5-50 \mathrm{~nm}$ [9].

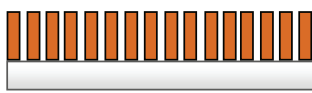

Nanopillar array electrode. Rods are $\sim 20-500 \mathrm{~nm}$ in width $[1,2]$.

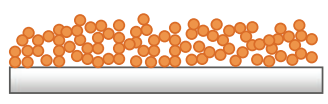

Nanoparticle-based gold electrode prepared from gold nanoparticles $(5-50 \mathrm{~nm})[5,6]$.

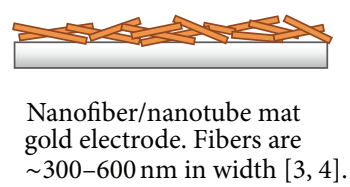

FIGURE 1: Some examples of high surface area nanostructured gold electrodes.

\section{What Are Nanoporous Gold Electrodes?}

Nanoporous electrodes are electrodes that contain a defined 3D network of nanometer size pores and ligaments [9]. Nanoporous electrodes have also be entermed "microporous" or "mesoporous" electrodes [18, 32-36] as this is the IUPAC definition of a material with $0.2-2 \mathrm{~nm}$ and $2-50 \mathrm{~nm}$ pores, respectively. They may also be referred to as nanoporous foams [37], particularly when they are in a monolithic form. In this paper, the focus will be on nanoporous gold made through dealloying, either chemically or electrochemically [9]. For example, 12 Karat white gold leaf ( 50:50 Au:Ag alloy) can be immersed in concentrated nitric acid for a short period of time. The nitric acid selectively dissolves the silver, but not the more noble constituent, gold. Nanoporous gold consists of a bicontinuous nanostructure with pores and ligaments in the nanometer size range [9]. In many respects, they are a conducting version of a silica aerogel: an open, foam-like 3D structure of nanometer sized pores accessible to species in solution or the vapor phase [37]. A representative SEM image of surface of a nanoporous gold electrode made in our lab by dealloying $12 \mathrm{~K}$ white gold leaf and capturing it on a gold slide is shown in Figure 2. As can be seen, the structure consists of pores that are $\sim 25-35 \mathrm{~nm}$ in diameter and ligaments that are $\sim 50-75 \mathrm{~nm}$ in width. As described in more detail below, the size of the pores and ligaments can be tailored via judicious choice in the composition of the alloy and the dealloying conditions. An example is shown in Figure 3.

The one important feature that distinguishes nanoporous electrodes from other types of high surface area electrodes is their very high surface areas coupled with an interconnected pore framework. Depending on how the electrode is made, surface areas that are 100s of times larger than planar gold are possible. High surface area-to-volume ratios coupled with an interconnected pore framework, high electrical conductivity, good mechanical properties, and ease of preparation has put this material at the forefront of analytical chemistry in the last few years [12, 13, 15, 28, 39]. Nanoporous gold electrodes have thus found numerous applications in heterogeneous catalysis, electrocatalysis, fuel cells, as electrochemical supercapacitors and as actuators, in chemical sensing, and supports for surface enhanced Raman Spectroscopy [12, 13, 15, 39].

\section{Fabrication}

A number of methods have been used to fabricate nanoporous gold in a variety of different forms including monoliths, nanowires, thin films, and ribbons [40-42], and most recently, nanoparticles [5] and nanoprisms [43]. Fabrication begins with an alloy of a defined composition and is followed by dealloying, either electrochemically or chemically, to remove the least noble constituent. Structural rearrangement of the most noble constituent takes place leaving a network of pores and ligaments of a defined size.

3.1. Alloy Preparation. The binary alloy that is most popular is $\mathrm{Au}: \mathrm{Ag}$, with a composition of $\mathrm{Au}_{65} \mathrm{Ag}_{35}$ (at \%). The alloy can be obtained in a number of different ways including (a) electrodeposition, (b) thermal (electron beam) evaporation, (c) sputter coating, (d) high temperature melting followed by cold rolling and annealing [44], or (e) commercially from various sources [9]. It is also possible to start with selfassembled films containing metal nanoparticles [5].

3.1.1. Electrodeposition. Au:Ag alloys in the form of a thin film, multilayer, a rod (e.g., wire), or in a suitable template can be made via electrodeposition [45-49]. In this case, $\mathrm{Ag}$ and Au cyanide salts [45-47] (or other salts in a thiosulfate solution [50]) are combined in a given ratio. Upon application of a sufficiently reductive potential to a working electrode immersed in this solution, the two salts can be electrodeposited together yielding the binary alloy. Au electrodeposition is kinetically favored, while Ag deposition is thermodynamically favored [45, 47]. Films of varying Au:Ag atomic percent can be made by altering the deposition potential and/or solution composition [51]. To form nanoporous wires or vertical nanoporous rods, electrodeposition can be carried out in membranes containing an array of cylindrical 


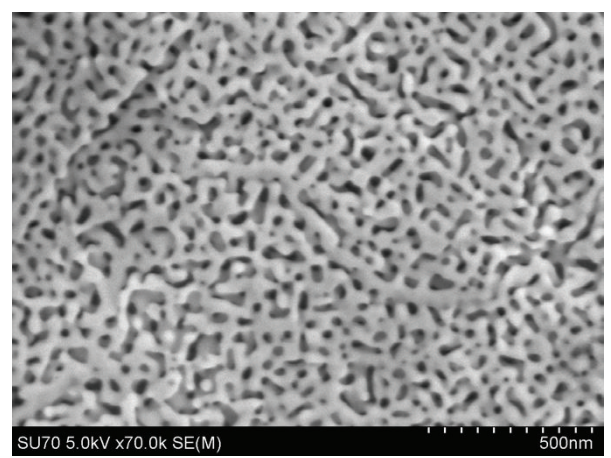

FIGURE 2: SEM image of nanoporous gold prepared by chemically dealloying 12 Karat gold leaf.
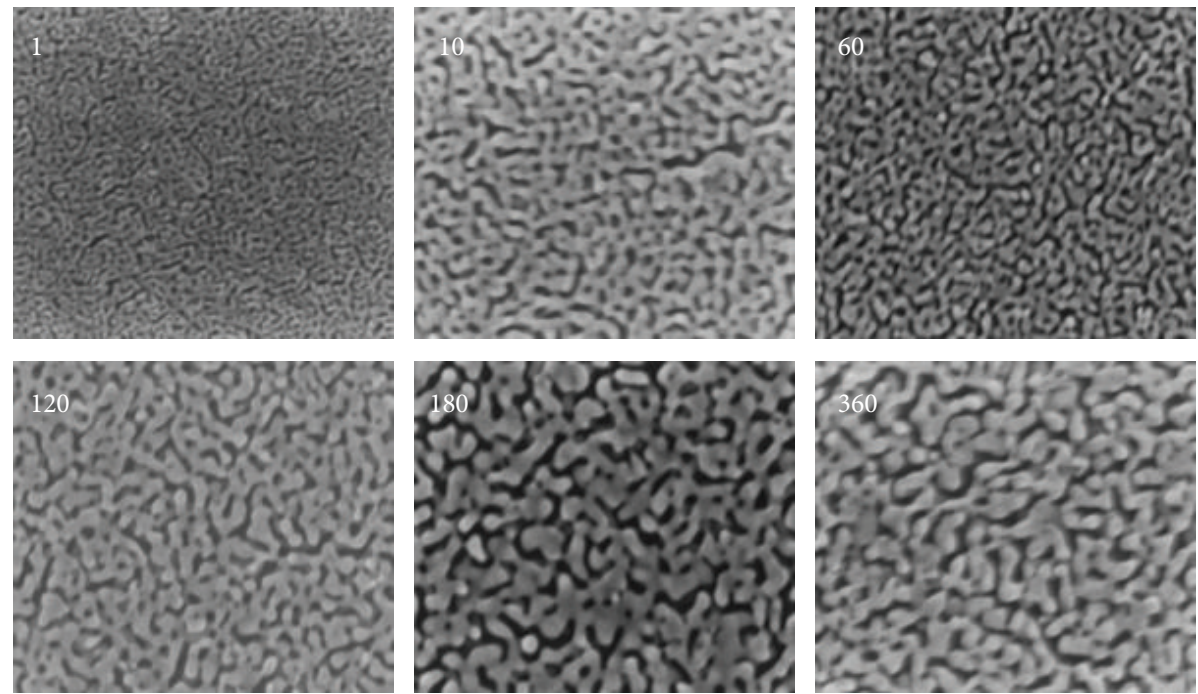

FIGURE 3: SEM images (150,000x) of nanoporous gold ( $80 \mathrm{~nm}$ ) prepared by chemical dealloying for different times (in minutes) [38]. Reprinted from SI with permission from [38].

nanosized pores [52-56]. For example, Ji and Searson have used this approach to prepare nanoporous gold nanowires and films $[53,54]$. Loacharoensuk and coworkers took this one step further and demonstrated the fabrication of "shapetailored porous gold nanowires" via sequential electrodeposition of $\mathrm{Au} / \mathrm{Ag}$ solutions of different composition in the pores of a gold-coated alumina oxide nanoporous membrane [55]. Yoo and Park fabricated porous gold vertical nanorods arrays and decorated them with platinum [56]. An alternate strategy for the preparation of nanoporous nanowires that does not involve electrodeposition entails the deposition of gold on a silver nanowire formed via a polyol process. The Au:Ag alloy is formed when the surface gold atoms interdiffuse with the underlying silver atoms at an elevated temperature [57].

Four important aspects regarding electrodeposition are as follows: (1) it requires a conductive substrate; (2) it can be used to create alloys in a number of different configurations, most notably films of various thicknesses (controlled by potential and time) and nano- and micron-sized wires; (3) the composition (Au:Ag atomic ratio) can be easily manipulated by varying the solution composition and/or potential; (4) cyanide salts are often used, which are toxic; and (5) as the films become thick, cracking can be problematic during the dealloying process [15]. However, thermal annealing can help reduce the severity of this problem $[15,58]$.

3.1.2. Thermal Evaporation/Sputter Coating. Rather than electrochemically growing the alloy, it is also possible to form it via thermal or electron beam evaporation using high purity Ag and Au targets followed by annealing [59]. In one example, nanoporous gold nanoparticles were made by first starting with an Au:Ag bilayer film deposited on a silicon substrate using electron beam evaporation. The bilayer film was dewetted by annealing at $900^{\circ} \mathrm{C}$ under argon to form the alloy nanoparticles [60]. Likewise, cosputtering a coating from separate Ag and Au targets is conducive toward making nanoporous gold films of various compositions and thicknesses on different substrates [23, 38, 51, 61, 62] and can also be coupled with optical lithography to form patterns of nanoporous gold on a substrate $[63,64]$. Scanning electron microscopy-energy dispersive X-ray spectroscopy (SEM-EDX) can be used to evaluate atomic composition. The most relevant characteristics of this method are as follows: 
(1) the alloy composition can be easily tailored by using different gun power settings; film thickness can be changed via variations in the sputtering time; (2) the alloy is also formed directly on the surface; (3) adhesion can be a problem on some substrates; and (4) it provides a means to form the alloy in localized regions on the substrate [15]. In recent work, Sattayasamitsathit et al. compared the pore size and ligament size of nanoporous gold formed from electrodeposited Au:Ag alloys and cosputtered alloys [51]. On carbon, they noted that the electrodeposited alloy displayed a "rougher morphology with higher porosity" than that of the sputtered sample [51].

3.1.3. Commercial. A very popular and simple approach is to purchase a premade Au:Ag alloy of a defined composition from a jewelry, art store, or another location $[9,15] .12 \mathrm{~K}$ white gold leaf (Monarch brand), for example, is a 50:50 wt \% gold alloy with a thickness of $\sim 100-200 \mathrm{~nm}[9,15,65]$. The gold leaf has primarily been used for decorative purposes and can be purchased from a number of suppliers. Thicker pieces can also be purchased to make nanoporous gold in a monolithic form $[66,67]$. Because gold leaf is ultrathin it can be difficult to handle, particularly after dealloying when it is most fragile [15]. It is typically "captured" on a suitable substrate (e.g., gold electrode) rather than directly grown on the substrate. The major limitation of this method is that only leaves of a few compositions can be obtained.

3.1.4. Other Binary and Ternary Alloys. Nanoporous films have also been made via electrodeposition from alloys other than Au:Ag. For example, a Au-Zn alloy was formed via electrodeposition of $\mathrm{Zn}$ at a gold wire in an ionic liquid at elevated temperatures [68]. In another example, nanoporous films of copper, silver, and gold were prepared by starting with a Zn-metal alloy. In this case, zinc was electrodeposited on a gold foil and then the Au-Zn material was heated to form the alloy [21]. Aluminum:gold alloys of various compositions (e.g., $\mathrm{Al}_{80} \mathrm{Au}_{20}$ and $\mathrm{Al}_{70} \mathrm{Au}_{30}$ ) [40-42] have also been used to prepare nanoporous gold that consists of large sized channels 100 s of nanometers in size along with nanoporous walls containing the ligament pore structure. The nanostructure of the gold ribbons prepared in this manner can also be tailored via judicious choice of the dealloying conditions and the composition of the binary alloy [41].

In addition to binary alloys, it is also possible and sometime advantageous to start with a ternary alloy. In these materials, the least noble constituent is removed (typically Ag) leaving behind a nanoporous binary alloy. For example, Snyder et al. worked with $\mathrm{Ag}_{65}\left(\mathrm{Au}_{35-x} \mathrm{Pt}_{x}\right)$ with $0 \%<x<$ $7 \%$ alloys and showed that the addition of Pt modifies the morphology of the nanoporous metal and its chemical and physical characteristics [69]. The addition of Pt retards the diffusion of the Au atoms and thus influences the reorganization of gold, resulting in a finer nanoporous structure (pore size $<4 \mathrm{~nm}$ ) and less coarsening (improved stability) [69]. Also, Au-Pt-Cu alloys have been used to form a nanoporous Au-Pt binary alloy [70]. In this case, copper was removed via dealloying. Ternary alloys of platinum, aluminum, gold and palladium, aluminum, gold (e.g., $\mathrm{Al}_{66} \mathrm{Au}_{27.2} \mathrm{Pt}_{6.8}$ ) were used to form nanoporous gold containing small amounts of either Pt or Pd depending on the ternary alloy used [71-73]. Similar to the results observed by Wang et al. for the Au-Ag$\mathrm{Pt}$ alloy, the Al-Au-Pt (Pd) dealloyed samples were shown to have a different microstructure compared to the binary $\mathrm{Au}-\mathrm{Ag}$ alloys, in particular smaller ligament/channel sizes [72]. Likewise, nanoporous gold with a "dual microscopic length scale" was fabricated using a $\mathrm{Au}_{5} \mathrm{Pd}_{20} \mathrm{Ag}_{75}$ ternary alloy [74]. Jin and coworkers described the use of the resulting nanoporous $\mathrm{Au}-\mathrm{Pt}$ alloys as electrochemical actuators [75] and in the electrocatalytic oxidation of formic acid [50,73].

3.2. Dealloying. Au-Ag alloys are typically dealloyed in one of two ways, (1) chemically or (2) electrochemically. The pore structure of nanoporous gold depends on the method used to dealloy, the processing conditions (temperature, time, and electrolyte), and the initial composition of the alloy. The composition of the alloy strongly affects the porosity and surface area of the material regardless of the method used [58, 76-78]. Dealloying works over a narrow compositional range: $\sim 26$ to 36 at \% Au [58, 77, 78]. At high composition (greater than 36 at \% Au), the removal of silver was limited and the surfaces contained randomly distributed pores, whereas at lower than 26 at \% Au, more microscopic cracking was observed [77, 78]. A decrease in film thickness was also noticed upon dealloying [78].

One of the simplest methods to dealloy is chemically by immersing the material in concentrated nitric acid for a given period of time followed by rinsing with water. The time spent in the nitric acid influences the pore/ligament size and the percent Ag remaining in the nanoporous Au network. The longer the time in acid, the larger the pore sizes and the smaller the percent $\mathrm{Ag}$ that remains in the material. For $12 \mathrm{~K}$ white gold leaf that is $\sim 100 \mathrm{~nm}$ thick, an immersion time of 5 minutes in acid yielded an average pore size of $\sim 8 \mathrm{~nm}$ with $\sim 5 \%$ Ag remaining [9]. Increasing the time in acid to 15 minutes increased the pore structure to $\sim 15-20$ nanometer, whereas 1 day in acid yielded ligaments that were $\sim 40 \mathrm{~nm}$ [9]. Another account reports average pore sizes of $\sim 18,30,40$, and $50 \mathrm{~nm}$ after dealloying gold leaf in concentrated nitric acid at room temperature for $15 \mathrm{~min}, 2 \mathrm{hr}, 4 \mathrm{hr}$, and $8 \mathrm{hr}$, respectively [79]. Energy-dispersive X-ray spectroscopy (EDX) estimates of the residual silver concentration range from 7 at $\%$ to 1 at \% [79]. For significantly thicker pieces of alloy, a much longer immersion time is used (e.g., 24-48 hours) [66, 67]. Variables such as the concentration of the acid, length of time in the acid solution, and temperature of the solution are particularly important and will influence the size of the pores and ligaments as well as the surface area of the material. Dealloying at very low temperatures can result in significantly smaller pore sizes $(\sim 5 \mathrm{~nm})$, but could also lead to more Ag remaining in the materials [80]. Dealloying in dilute acid solutions can also lead to higher amounts of residual silver being present [38].

Electrochemical dealloying can be undertaken in a number of different ways. Typically the electrode is immersed in a dilute perchloric acid solution and a potential is applied (with respect to a reference electrode) for a given 
period of time from $\sim 10 \mathrm{~min}$ to over an hour $[44,81]$ to one to five days, depending on the thickness of the alloy [44]. A number of other electrolyte solutions have also been used with good success including halide containing electrolytes, $\mathrm{AgClO} / 4 / \mathrm{HClO}_{4}, \mathrm{AgNO}_{3} / \mathrm{HNO}_{3}$, and neutral $\mathrm{pH} \mathrm{AgNO}_{3}$ solutions [22, 23, 44, 82, 83]. Dealloying can be performed under an elevated temperature [59] that can help decrease the time needed to dealloy [81] as well as improve the mechanical stability of the film [84]. The applied potential (current density), time, temperature, concentration, and $\mathrm{pH}$ of acid/electrolyte solution are important variables that influence the size of the pores/ligaments, the surface area, and the percent silver that remains in the nanostructure [85]. Dealloying in neutral $\mathrm{pH}$ silver nitrate solutions resulted in smaller pore sizes and a three-fold higher surface area compared to dealloying in concentrated nitric acid [83]. Four noteworthy features about electrochemical dealloying $\mathrm{Au}-\mathrm{Ag}$ binary alloys are as follows: (1) the kinetics of the dealloying process can be followed and studied by monitoring the current density resulting from the dissolution of $\mathrm{Ag}$ from the alloy surface [85]; (2) the electrolyte solutions chosen are significantly less corrosive than concentrated nitric acid [83]; (3) the nanoporous gold has to be in electrical contact to dealloy [15]; and (4) the pore/ligament structure can be controlled to a certain extent by the magnitude of the applied potential [86].

3.3. Mechanism of Pore Evolution. The mechanism for pore formation has been extensively investigated by the research groups of Erlebacher et al. [87-89] and others and has been well summarized in a number of reviews $[9,15,27]$. In brief, the evolution of porosity begins with the dissolution of the least noble consistent-silver-on the outer most surface of the homogeneous Au:Ag binary alloy [88]. During the removal of silver, the gold atoms, which diffuse very quickly at the electrolyte/metal interface, move and restructure on the surface to form gold-rich clusters surrounded by holes/pits. This exposes additional Ag, which dissolves and leads to additional reorganization of the gold atoms and the exposure of more $\mathrm{Ag}$ [88]. At some point, the gold rich clusters turn into hills/mounds that become undercut leading to the formation of new clusters. Through this process of dissolution/reorganization, the pore morphology of nanoporous gold develops and the silver becomes depleted [88]. Figure 4 shows a schematic of this process (reproduced with permission of The Electrochemical Society [88]). The pore structure continues to evolve over time leading to an increase in pore/ligament size and continued reduction in silver.

\section{Characterization}

The physical and chemical properties of nanoporous gold have been studied using a number of different methods. Characterization of the physical properties of the materials formed after dealloying has been done predominately by scanning electron microscopy (SEM), atomic force microscopy (AFM), scanning tunneling microscopy (STM), transmission electron microscopy (TEM), tomography, X-ray diffraction (XRD) and small angle X-ray diffraction (SAXS), and electrochemical methods while characterization of the elemental composition has been done by X-ray photoelectron spectroscopy (XPS) or Auger spectroscopy and scanning electron microscopy-energy dispersive X-ray spectroscopy (SEM-EDX). Some of the more common methods for the characterization of nanoporous gold relevant to the analytical chemist are briefly described below.

4.1. Microscopic Methods. Of all the microscopic methods of analysis, SEM is one of the most widely used tools to characterize the surface morphology of nanoporous gold. In the case of nanoporous gold, relatively high-resolution SEM images (see e.g., Figures 2 and 3,) can provide valuable information about the pore size and ligament size of a sample and allow for comparisons to be readily made between samples prepared under different dealloying conditions. Low magnification images can provide valuable information about the presence and extent of microscopic cracking in the sample. Because nanoporous gold is already conductive, there is no need to first coat the samples with a fine layer of metal, and high-quality images can be obtained. Unlike TEM, thick samples can be quickly imaged. When SEM is coupled with $\mathrm{EDX}$, the atomic percent $\mathrm{Ag}$ and $\mathrm{Au}$ in the bulk of the material can be readily determined with knowledge of the atomic sensitivity factors. Likewise, such elemental information can also be obtained from TEM, though thin sections need to be made.

AFM has also been used to obtain information regarding pore/ligament size. AFM has the advantage that it can be performed under atmospheric conditions (does not require a vacuum) but it can take some time to collect a high-resolution image of a large size and the images have the potential to be distorted by tip artifacts. Because AFM is ideal for imaging samples under ambient conditions, this technique is useful for examining biomolecules adsorbed on surfaces. In recent work, a nanoporous gold monolith was cleaved and AFM was used to evaluate the presence and orientation of proteins on the surface [90].

The three-dimensional (3D) structure of nanoporous gold with high resolution has recently been acquired using transmission electron tomography [91, 92]. A 3D image of nanoporous gold is shown in Figure 5 [91]. This method is an ideal way to see the inner pore network, the bicontinuous nature of nanoporous gold, and quantitatively evaluate the curvature and the average diameter of the ligaments and nanopore channels [91, 92]. Transmission X-ray microscopy using a synchrotron X-ray source has also been used to examine the 3D microstructure of a coarsened sample tens of microns thick [93]. Recently, this method has been used to study the coarsening of nanoporous gold at different temperatures [94].

4.2. Spectroscopic Methods. Both SEM-EDX and XPS have been used to evaluate the percent Ag remaining in the nanoporous gold framework after dealloying. The major difference between the two techniques is that EDX reports on 

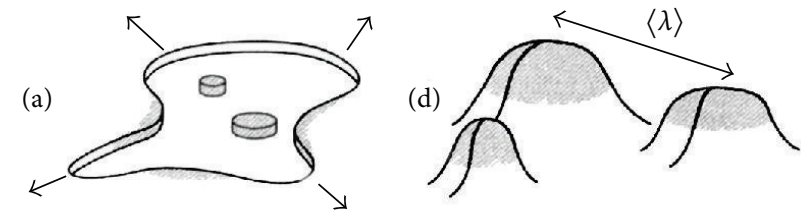

(b)
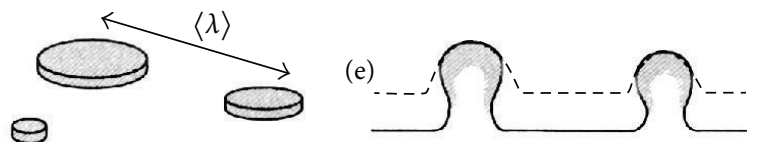

(c)
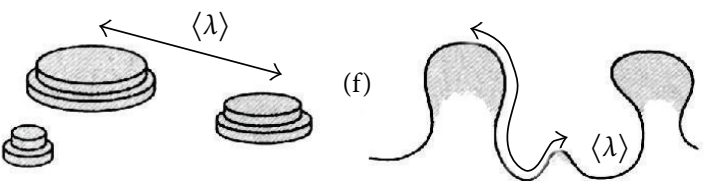

FIGURE 4: Evolution in porosity during the dealloying of a Au:Ag alloy [88]. Shaded regions represent Au; uncolored regions represent Ag. Reproduced by permission of The Electrochemical Society from [88].

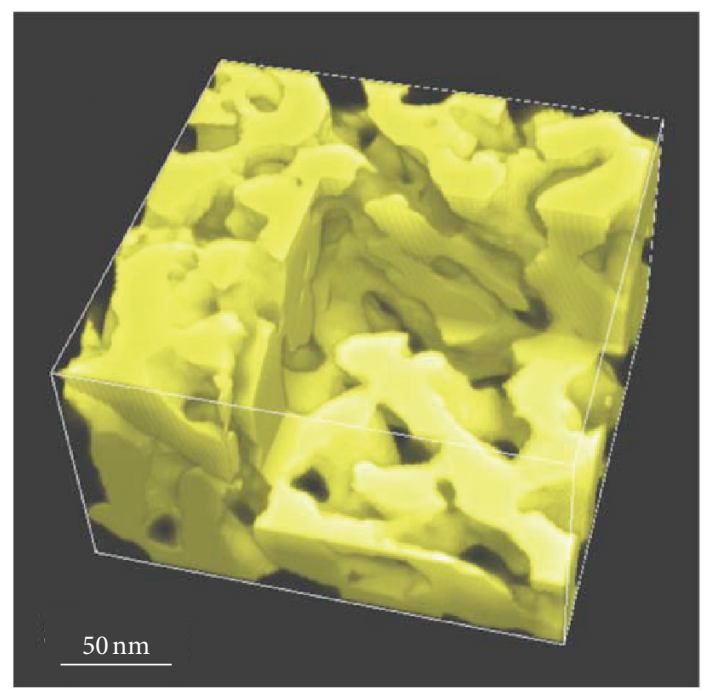

FIGURE 5: 3D reconstructed TEM tomography image showing the internal structure of nanoporous gold [91]. Reprinted with permission from [91].

the bulk Ag concentration where XPS reports on the percent Ag on the top few nanometers of the surface. These two values are typically not the same, often 5-10 times different from each other $[95,96]$. XPS also provides an important route to evaluate the extent of surface contamination on the surface of nanoporous gold, particularly after treatment. For example, high-resolution core level spectroscopy has been used to examine how the surface chemistry of nanoporous gold changes with/without thermal treatment under oxidizing conditions $[95,97]$. In particular, significant information about the nature of the gold oxide, the presence of metallic gold, the different types of oxygen species present on the surface, the chemical state of Ag, and the presence of surface enrichment has been obtained [97].

4.3. Electrochemical Methods. Electrochemical methods provide a useful and straightforward way to measure the surface area of nanoporous gold and allow comparisons to be readily made to planar gold [64]. Perhaps one of the most common methods involves the formation and successive reduction of gold oxide in sulfuric acid [64, 67]. Using cyclic voltammetry $(\mathrm{CV})$ at slow scan rates, the charge associated with the reduction of gold oxide, which is proportional to the real surface area of the electrode, is measured $[64,67]$. The roughness factor of the electrode can be calculated by taking the ratio of the real surface area to the geometric surface area. In contrast to gas sorption measurements (see later section), this method can measure the surface area of thin nanoporous gold films.

Other electrochemical methods have also been used to assess the surface area of nanoporous films. The underpotential deposition (UPD) of metal $\left(\mathrm{Pb}^{2+}, \mathrm{Cu}^{2+}, \mathrm{Ag}^{+}\right)$, whereby the charge from the formation or stripping of the UPD monolayer is measured via chronoamperometry or $\mathrm{CV}$, has been used $[50,64,65,98]$. In this case, the charge measured of a UPD monolayer is directly proportional to the surface area of the electrode [98]. A detailed analysis of the UPD mechanism and kinetics of $\mathrm{Pb}$ UPD on nanoporous gold electrodes have been reported [98]. These authors and others have noted that UPD is more complicated on nanoporous gold relative to planar gold because of mass transport limitations [64, 98].

Another electrochemical approach involves electrochemical impedance spectroscopy (EIS) or CV $[83,99]$ to evaluate the double-layer capacitance of the electrode, which is proportional to electrode area. EIS can be a little tricky because it relies on the model chosen and fitting procedures [98]. 
The presence of residual silver can also increase the capacitance of the electrode [83].

Detsi et al. reported that the area measured using gas sorption was lower than that measured electrochemically, which they attributed to assumptions made in the electrochemical analysis [99]. In another article, however, comparable albeit lower values were obtained relative to gas adsorption when using $\mathrm{CV}$ to measure the charge required to strip the gold oxide films [67]. Rouya et al. compared $\mathrm{Cu}$ UPD, EIS, and the $\mathrm{AuO} / \mathrm{Au}$ redox reaction and showed that $\mathrm{Cu}$ UPD and $\mathrm{AuO} / \mathrm{Au}$ gave nearly identical values of area, while EIS values were found to be 1.5 to 1.75 times larger [64]. The authors postulated that the presence of Ag at surface may be an influencing factor or the curvature of the ligaments in the nanoporous gold material [64].

Electrochemical methods, particularly, voltammetry can also be used to evaluate how much of the electrode area is electrochemically useful to a redox species in solution. This is important because the electrochemistry that takes place at high surface area nanostructured electrodes is very different from that which takes place at a conventional planar electrode or ultramicroelectrode $[14,100]$. In a cyclic voltammetry (CV) experiment, the Randles-Sevcik equation predicts that Faradaic current scales linearly with electrode area when all other variables are constant. However, what is observed experimentally at a nanoporous gold electrode is a 10 -fold increase in area that does not always lead to a 10 -fold increase in the peak Faradaic current. For a redox molecule in solution that exchanges electrons quickly at an electrode surface (large standard rate constant, $k^{0}$ ), the observed increase in Faradaic current was found to be only a few percent of what it should have been theoretically based on the "real" electrode area [24]. For redox couples with slow electron transfer kinetics, however, the opposite was observed [24]. A large enhancement in current was noted, consistent with increased electrode area. These results indicate that high surface area porous electrodes are biased toward redox couples that have slow rates of electron exchange [14]. The reason for this is because for a redox species (Ox) with fast kinetics, the concentration of $\mathrm{Ox}([\mathrm{Ox}])$ at the outermost pore layer drops to zero; therefore, $[\mathrm{Ox}] \sim 0$ in the inner pore, meaning that the inner surface is "not useful" $[24,100,101]$. For a slow redox reaction, $[\mathrm{Ox}]$ at the outerpore does not fall to zero and the inner surface is thus used. A simple cartoon of this effect is presented in Figure 6. In Figure 6(a), almost all of $O$ (oxidized form of the redox couple) reacts at the outskirts of the nanopores because the electron transfer kinetics are fast, whereas in Figure 6(b), the reduction of $\mathrm{O}$ to $\mathrm{R}$ (reduced form of the redox couple) takes place deeper inside the nanopores because electron transfer is slow. Thus more of the electrode area is used. As Park et al. put it, "discriminative amplification" takes place at nanoporous electrodes [14].

4.4. Gas Sorption Methods. A standard means to measure the surface area and pore sizes of high surface area nanostructured materials involves collecting nitrogen adsorption/desorption isotherms and then utilizing BET theory and the $\mathrm{BJH}$ method to measure surface area and evaluate pore

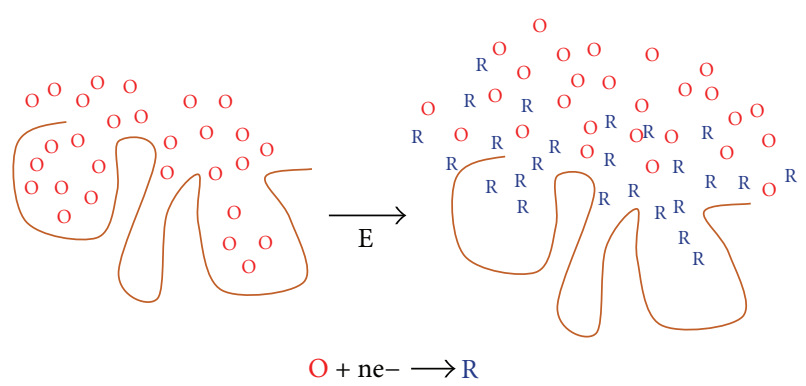

(a) Fast electron transfer

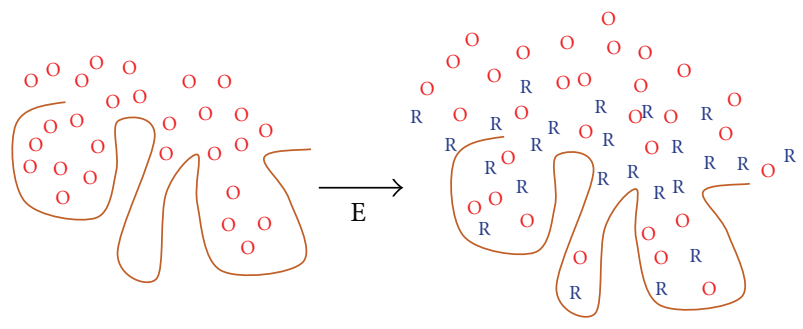

(b) Slow electron transfer

FIGURE 6: "Discriminative amplification" at nanoporous electrodes [14].

size distribution, respectively. For this measurement to work for nanoporous gold, a sufficiently high mass must be used $[98,99]$. This negates the use of thin films but rather requires large monolithic pieces in order to have enough material to make the measurements. Type IV isotherms with H1type hysteresis characteristic of a mesoporous material and BET surface areas of several meters square per gram (e.g., $\sim 3-10 \mathrm{~m}^{2} / \mathrm{g}$ ) have been obtained [66, 67, 99]. Coarsening observed at higher temperatures decreases the BET surface area and decreases pore volume [67]. One potential area of concern with gas sorption methods is the temperature used to outgas the material. Because nanoporous gold can undergo coarsening at elevated temperatures (see the section that follows), it is possible that lower surface areas can be obtained using this method [98]. One approach to measure the BET surface area for thin films involves using a quartz crystal microbalance (QCM) measuring system [38]. Surface areas obtained with this QCM approach as compared with that obtained via measurement of electrochemical capacitance were within $30 \%$ [38].

\section{Specific Features of Nanoporous Gold}

One of the nice features about dealloying as a method to produce nanoporous gold is that the pores are open and extend through the material into the bulk. Nanoporous gold also has a high density of low coordination surface gold atoms, which are believed to play an important role in catalysis [39]. The pore structure, particularly the surface area, pore size, and ligament size of the nanoporous gold can be controlled to a large extent by factors such as alloy composition, dealloying 
parameters and processes, temperature, and by postalloy processing $[15,39,102]$. Dealloying variables such as the concentration of the acid, length of time in the acid solution, applied potential, and temperature of the etchant solution are particularly important [15]. Posttreatments include thermal and acid treatment $[9,15,67,103]$. One means to decrease pore size while keeping the ligament size nearly the same is via the electroless plating of gold into the internal surfaces of nanoporous gold $[104,105]$.

Another useful feature of nanoporous gold is that it can be readily modified by exploiting gold-sulfur chemistry to form a self-assembled monolayer (SAM) from functionalized organothiols. These SAMs can act as simple modifiers [68] or be used as linkers to attach various molecules to its surface such as proteins, enzymes, antibodies, or photosystem I $[65,66,90,106-109]$. Because of the very high surface areas of nanoporous gold, a significantly larger amount of the modifier can be immobilized on its surface relative to a planar gold electrode. Thus, surface modification/adsorption can potentially lead to significantly better detection limits. However, the long-range organization of SAM on nanoporous gold could be very different than on planar gold because of the intricate curved surface and porosity $[90,110]$. Mass transport limitations associated with the nanoporous network (see below) could also make modification of the inner surfaces more difficult [90]. The presence of residual silver could also complicate the chemistry of immobilization $[62,111]$. Various studies have shown that the surface coverage, spacing, and degree of interactions between neighboring molecules can be different on nanoporous gold versus planar gold $[90,110$, 111]. Likewise, electron transfer between a redox species in solution with the underlying gold surface can also be different and more complex [110].

Nanoporous gold formed by dealloying Au-Ag alloys also has several additional characteristics (positive and negative) that need to be kept in mind. First, very rarely is all the silver removed during the dealloying process. The bulk Ag concentration in the resulting nanoporous gold materials can amount to a 0.1 atomic percent to over $20 \%$. Trace amounts of silver can complicate the chemistry taking place at the interface, which can either be construed as a good thing or a bad thing depending on the outcome. In the catalytic oxidation of $\mathrm{CO}$, the presence of small amounts of silver has been shown to play an important role $[95,96,112]$. In contrast, for methanol oxidation, increases in Ag do not improve activity [113]. Ag has also been shown to contribute to the SERS enhancement observed at nanoporous gold [114] and has also been shown to influence the electrochemically measured surface area $[64,83]$. As described, scanning electron microscopy-energy dispersive spectroscopy (SEMEDX) can help evaluate the bulk concentration of silver, whereas X-ray photoelectron spectroscopy (XPS) can aid in determination of the surface concentration of silver, which typically is the most relevant. The two values obtained are often very different from each other.

Second, the microstructure of nanoporous gold is inherently unstable at elevated temperatures and coarsens over time, which gives rise to larger ligament sizes and also brings silver to the surface [27]. Coarsening can be good in that it provides an easy means to increase the pore/ligament size but it can also be construed as bad in that it also limits how small of a pore size can be obtained [27]. Coarsening that takes place at elevated temperatures can also influence the measurement of surface area via gas sorption analysis (see earlier section) [98]. To reduce coarsening and to also obtain smaller pores, several approaches have been used. Snyder et al. [69] and later others $[70,75]$ have shown that the addition of Pt to the Au-Ag alloy can help to reduce coarsening and also enable smaller pore sizes to be obtained. Biener et al. noted that adsorbed oxygen from ozone decomposition helps to stabilize the nanostructure against coarsening at low temperatures [115]. More recently, atomic layer deposition was used to form a very thin layer of $\mathrm{Al}_{2} \mathrm{O}_{3}$ or $\mathrm{TiO}_{2}$ on nanoporous gold, which helped to suppress coarsening and improve thermal stability [116].

Third, relatively thick films constrained on a surface can crack due to the large stress that takes place during the dissolution of $\mathrm{Ag}$ atoms [15, 50, 58]. Cracking can be minimized/eliminated by careful control of the parameters in the dealloying process [28, 59, 77, 84]. For example, Kim and coworkers preferred to electrochemically dealloy in dilute perchloric acid under an elevated temperature to minimize/eliminate cracking [59]. Under these conditions, the dissolution rate of $\mathrm{Ag}$ atoms is slow while $\mathrm{Au}$ diffusion is fast [59]. Senior and Newman showed that application of the appropriate dealloying potential coupled with an increase in temperature can give rise to materials with better mechanical stability [84]. A multistep galvanostatic method to dealloy using multiple steps and different acid concentrations has also been proposed [117]. In chemical dealloying, cracking can also be lessened by optimizing the composition of the alloy $[58,77]$ by diluting the nitric acid solution [118], or by thermally treating the alloy films at elevated temperatures $\left(300^{\circ} \mathrm{C}\right)$ prior to chemical dealloying [58]. However, cracking is very dependent on film thickness. In one study, cracking could be observed in all the sputter coated films (thickness up to $2 \mu \mathrm{m}$ ) chemically dealloyed except for the $80 \mathrm{~nm}$ films [38].

Fourth, the entire surface of the nanoporous metalparticularly the inner surface-may NOT be fully accessible to a species in the gas phase or in solution on the time scale of the experiment. Nanoporous gold with an extremely high surface area may not be that important if all surface area is not available for modification and/or accessible to an analyte in solution. Restricted diffusion and pore blocking can be very relevant in nanoporous with very small pore sizes and hence large surface areas. Mass transport restrictions can be very important in high surface area materials with narrow pore size distributions [113]. There have been several approaches to deal with mass transport limitations. Increasing the pore sizes via controlled coarsening can help [113]. Early on, Ding and Erlebacher proposed the use of a two-step dealloying process to generate a multimodal pore network [119]. For example, the Au-Ag alloy was immersed in nitric acid and then thermally coarsened at a higher temperature to yield significantly larger pore network. The nanoporous gold was then filled with $\mathrm{Ag}$, annealed, and redealloyed to yield a material with a multimodal pore structure [119]. More recent 
approaches have involved the formation of a hierarchical pore network consisting of nanosized pores and/or macroor mesopores $[49,51,120]$.

\section{Applications of Nanoporous Gold in Chemical Sensing}

Nanoporous gold is an ideal support for the development of chemical sensors. Important attributes include conductivity, high surface area, ease of modification, reasonable stability, tunable pore size, and a relatively open pore network. Because nanoporous gold is conductive, most of the sensing platforms described to date utilize some form of electrochemistry. As described in an earlier section, nanoporous electrodes work best, meaning that more of their electrode area is utilized, when the electroactive species being detected exhibits sluggish electron transfer kinetics. Nanoporous electrodes are also ideal for those experiments that involve some type of immobilized species. The high surface area of nanoporous gold allows a significantly higher amount of a reagent or analyte to be immobilized on its surface, thus allowing for the possibility of greater signals than what can be obtained with planar gold. However, it must be kept in mind that non-Faradaic current, which represents the "noise" in an electrochemistry experiment, also scales with electrode area. The detection of low concentrations of a species in solution often requires the use of more sensitive electrochemical techniques that minimize nonFaradaic current such as pulse voltammetric methods (e.g., differential pulse voltammetry and square wave voltammetry). Mass transport limitations, which will be influenced by pore sizes, are also important in sensing applications. There is often a trade-off between small pore size, which gives larger surface areas, but slower or more restricted mass transport. Experiments should be designed with this aspect in mind. For chemical sensing in particular, really large surface areas are valuable only when they can be fully utilized.

6.1. Electrochemical Immunosensors. An immunosensor is a device that detects the interaction between an antibody $(\mathrm{Ab})$ and an antigen ( $\mathrm{Ag}$ ) and, as such, has become an important analytical tool in clinical and pharmaceutical sciences [121123]. Nanoporous gold has two important characteristics that make them ideally suited for electrochemical immunosensing: high surface area coupled with an open framework. The high surface area enables a greater amount of antibody to be immobilized on the surface relative to that which can be obtained on a flat, planar surface. An open structure has the potential to provide greater access for the substrate to reach the immobilized enzyme-labeled antibody $\left(\mathrm{Ab}^{*}\right)$.

There have only been a few reports on nanoporous gold-based immunoassays, predominately by one research group. In one example, nanoporous gold was used in a sandwich immunoassay for the detection of hepatitis B [124]. A schematic of the fabrication of the sensor is shown in Figure 7 [124].

In this report, the hepatitis B antibody was covalently linked to the nanoporous gold framework via gold-thiol chemistry. Nonspecific adsorption was reduced/eliminated by adsorbing bovine serum albumin and the modified electrode incubated into a solution containing the antigen. Horseradish-peroxidase- (HRP-) labeled antibody was attached to gold nanoparticles and this solution dripped on to the modified electrode to form the sandwich complex. The concentration of the antigen was determined electrochemically. Specifically, HRP catalyzed the redox reaction between o-phenylenediamine (OPD) and $\mathrm{H}_{2} \mathrm{O}_{2}$ to form 2,3-diaminophenazine (DAP), which was electrochemically detected using differential pulse voltammetry [124]. The authors reported a linear range of $0.01-1.0 \mathrm{ng} / \mathrm{mL}$ with a detection limit of $2.3 \mathrm{pg} / \mathrm{mL}$ [124].

A label-free immunosensor for human serum chorionic gonadotropin (hCG), a marker for testicular and ovarian cancers, has also been recently described [125]. The sensor consisted of a glassy carbon electrode support onto which graphene was deposited followed by a nanoporous gold foil prepared by dealloying a gold foil in concentrated nitric acid at room temperature. Anit-hCG was placed on the surface; the modified electrode soaked in bovine serum albumin to reduce/eliminate nonspecific adsorption and then incubated in buffered solutions of hCG. A dilute Nafion solution was placed over the electrode to hold everything in place. Hydroquinone served as the redox probe. The sensor had a linear range of $0.5-40 \mathrm{ng} / \mathrm{mL}$ and a detection limit of $0.034 \mathrm{ng} / \mathrm{mL}[125]$.

In another related study, the detection of kanamycin, an antibiotic used in veterinary medicine, was described using this label-free immunosensor strategy [126]. In this study, the glassy carbon electrode was coated with graphene and soaked in a Prussian blue-chitosan solution. Nanoporous gold was placed on top followed by kanamycin antibody, bovine serum albumin, and incubated in different concentrations of kanamycin. The linear range for this sensor was reported to be 0.02 to $14 \mathrm{ng} / \mathrm{mL}$ with a detection limit of $6.31 \mathrm{pg} / \mathrm{mL}$ [126]. In another similar study, prostatespecific antigen (PSA) served as the analyte using an antiPSA antibody-immobilized nanoporous gold film on glassy carbon and potassium ferricyanide as the redox probe was described [127]. The linear range was reported to be $0.05-$ $26 \mathrm{ng} / \mathrm{mL}$ with a detection limit of $3 \mathrm{pg} / \mathrm{mL}$ [127]. In all three studies, the dealloying time, which influences pore size and the amount of residual silver, was investigated [125-127].

Sandwich-type immunosensors have also been described for the detection of carcinoembryonic (CEA) antigen and the cancer antigen 15-3 (CA-15-3) [128, 129]. In the former, the sensor was based on the electrochemiluminescent reaction of ruthenium (II) tris(bipyridine) $\left(\mathrm{Ru}(\mathrm{bpy})_{3}{ }^{2+}\right)$ with tripropylamine. The $\mathrm{Ru}(\mathrm{bpy})_{3}{ }^{2+}$ was doped into silica nanoparticles functionalized with amine groups and then attached to nanoporous gold and further labeled with anti-CEA [128]. A detection limit of $0.8 \mathrm{pg} / \mathrm{mL}$ was obtained. For the latter immunosensor, thionine-nanoporous goldgraphene served as the sensor platform and horseradish-peroxidase- (HRP-) encapsulated liposomes served as labels. A detection limit of $5 \times 10^{-6} \mathrm{U} / \mathrm{mL}$ was reported [129]. 

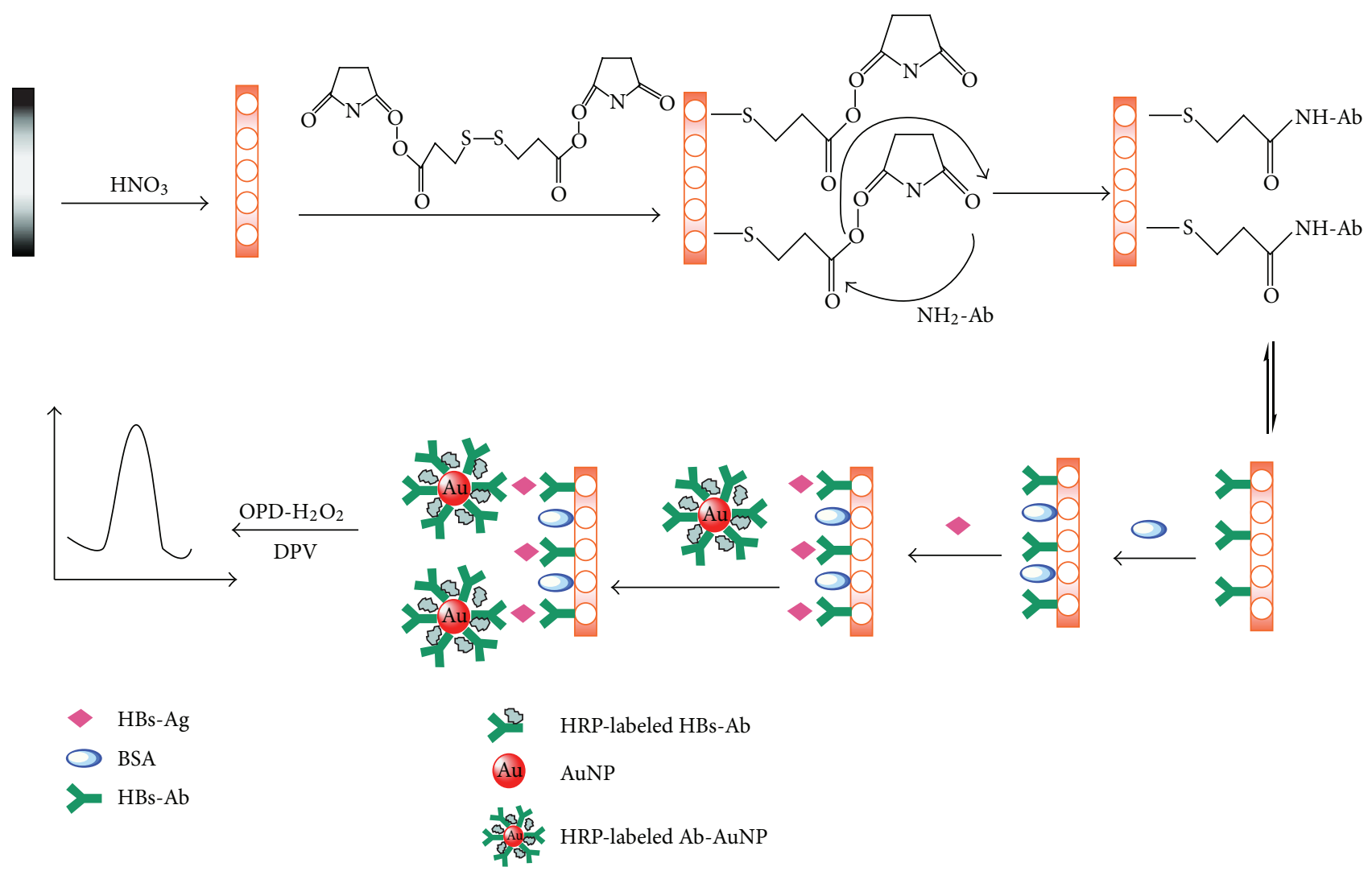

FIGURE 7: Schematic of an immunosensor for hepatitis B [124]. Reprinted with permission from [124].

6.2. DNA Sensors. There have been several reports on DNA sensors using nanoporous gold electrodes as a high surface area conductive support. These studies involve the formation of sandwich assemblies between capture, target, and reporter (probe) DNA. In these reports, modified capture-DNA, which is immobilized on nanoporous gold, has a sequence that is complementary to target DNA which has a sequence complementary to reporter (probe DNA). Together they form a sandwich complex on the surface of nanoporous gold. Detection takes place electrochemically.

One early report described a DNA biosensor formed by using nanoporous gold as the solid support and gold nanoparticles labeled with two oligonucleotides, one of which was complementary to a target DNA and the other to a reporter strand [130]. A schematic of the fabrication of this sensor can be seen in Figure 8 [130].

In this work, a nanoporous gold film was captured on a glassy carbon electrode and then modified with a thiolated DNA sequence (capture DNA) via gold-thiol chemistry followed by mercaptohexanol and incubation with a target DNA. The DNA-modified nanoporous gold electrode was then hybridized with the DNA-modified gold nanoparticles [130]. When placed in an electrolyte solution containing $\mathrm{Ru}\left(\mathrm{NH}_{3}\right)_{6}{ }^{3+}$, electrostatic interactions with the reporter DNA took place. The chronocoulometric electrochemical signal measured was proportional to the amount of reporter DNA and ultimately to the concentration of the target DNA. A plot of the chronocoulometric response with concentration was linear from $8.0 \times 10^{-17}$ to $8.0 \times 10^{-16} \mathrm{M}$ and a detection limit of $2.8 \times 10^{-17} \mathrm{M}$ was found. The authors indicated that the detection limit had a 300 -fold improvement relative to a bare flat electrode [130]. This report was followed up by another study that used differential pulse anodic stripping voltammetry as the detection method [131]. In this example, the gold nanoparticles contained reporter DNA and signal DNA modified with $\mathrm{PbS}$ nanoparticles. The authors report a linear range from $9 \times 10^{-16}$ to $7 \times 10^{-14} \mathrm{M}$ and a detection limit of $2.6 \times 10^{-16} \mathrm{M}[131]$.

In another example of a DNA biosensor, the detection method was based on the electrochemiluminescent reaction between a precursor in solution with $\mathrm{CdTe}$ quantum dots (QD) attached to a DNA sandwich assembly [132]. First, amine-modified capture-DNA was immobilized to the surface of a TGA-modified nanoporous gold electrode. Unbound TGA was blocked with bovine serum albumin. This capture-DNA electrode was then hybridized with targetDNA followed by incubation with probe-DNA. Because the target-DNA had a complementary sequence to both capture and probe-DNA, a sandwich complex formed on the nanoporous gold electrode support. Amine groups on the ends of the sandwich complex were attached to mercaptopropionic acid-capped CdTe QDs via carbodiimide chemistry. The electrogenerated chemiluminescence between peroxydisulfate $\left(\mathrm{S}_{2} \mathrm{O}_{8}{ }^{2-}\right)$ in solution and the CdTe QDs was measured. The authors report a detection limit of $2.7 \times$ $10^{-15} \mathrm{M}[132]$. 


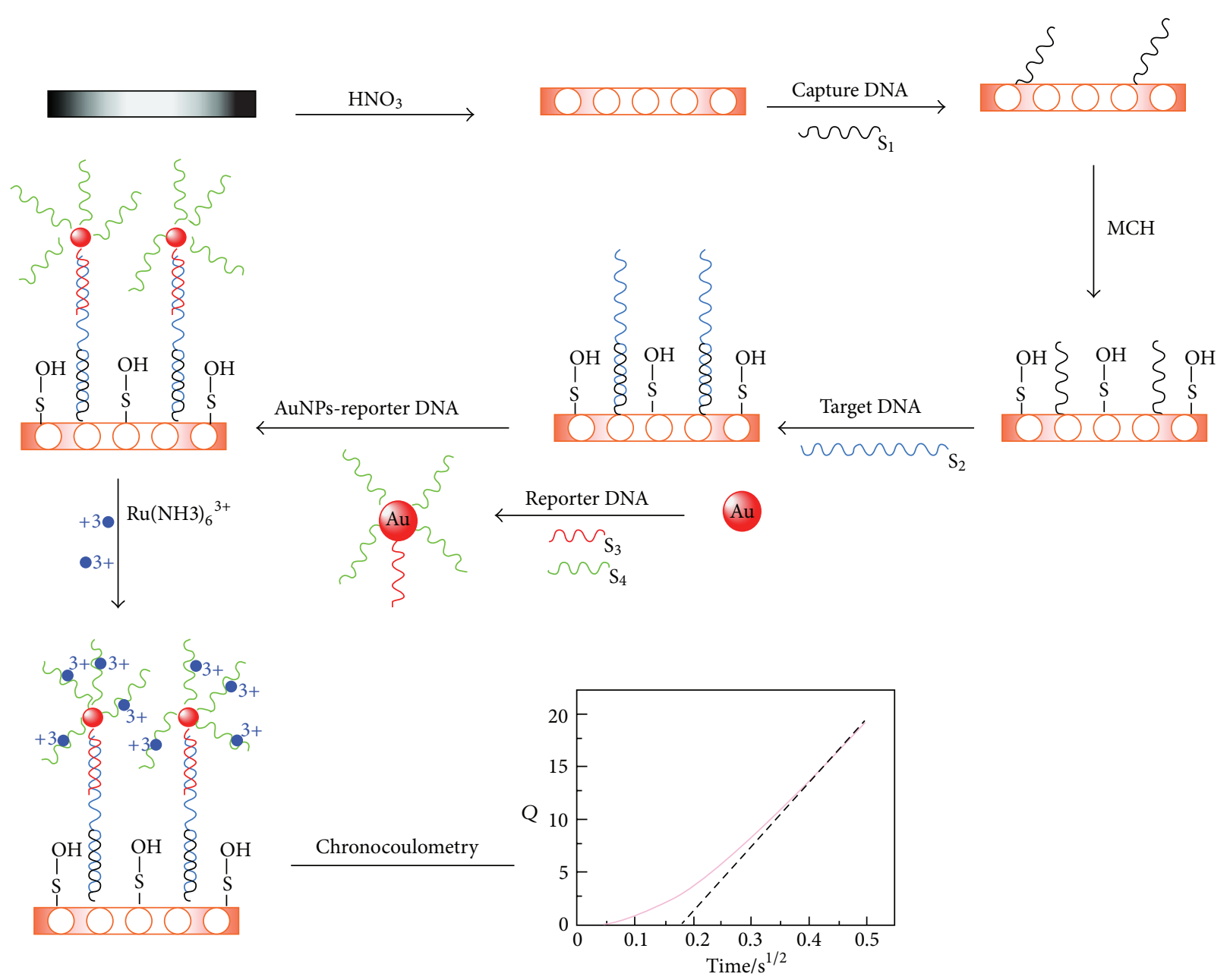

Figure 8: Schematic of a DNA biosensor [130]. Reprinted with permission from [130].

In a more recent example, an electrochemiluminescence assay based on a nanoporous gold electrode and $\mathrm{PdCu}$ nanocomposites bound to carbon nanocrystals via cysteaminecarbodiimide coupling was described [133]. Similar to the study described earlier [130], nanoporous gold was fabricated by dealloying commercial gold leaf and capturing on a glassy carbon electrode. The modified electrode was then incubated with a DNA capture probe, treated with mercaptohexanol, immersed in a solution containing the target DNA, and then hybridized to the $\mathrm{PdCu}$ carbon nanocrystals labeled with reporter DNA. ECL between the carbon nanocrystals loaded on $\mathrm{PdCu}$ and peroxydisulfate $\left(\mathrm{S}_{2} \mathrm{O}_{8}{ }^{2-}\right)$ in solution was measured and related to the concentration of the target DNA. The authors report a linear range from 0.05 to $8000 \times 10^{-15} \mathrm{M}$ with a detection limit of $1.8 \times 10^{-17} \mathrm{M}$ [133].

6.3. Enzyme-Based Biosensors. Nanoporous electrodes can be used to fabricate biosensors using an enzyme immobilized on its surface. Enzyme-immobilized nanoporous gold is also applicable for the construction of biofuel cells [134, 135]. One of the most important advantages nanoporous gold has over planar gold is a significantly larger area allowing for a greater amount of enzyme to be immobilized on the electrode and potentially larger signals to be obtained. Other favorable characteristics of nanoporous materials, in general, include the stabilization of the immobilized enzyme against denaturation, better thermal stability, and reduction in leaching [136, 137]. Porous materials have been shown to be a good support for the immobilization of enzymes because the constrained environment can help stabilize the macromolecule under otherwise denaturing environments such as in an organic solvent or at high temperatures $[138,139]$. The research groups of Wang et al., for example, have recently studied the thermal and organic solvent stability of enzymes (lipase, $5 \mathrm{~nm}$; catalase, $10 \mathrm{~nm}$; and horseradish peroxidase, $4 \mathrm{~nm}$ ) immobilized in nanoporous gold with an average pore size of $35 \mathrm{~nm}$ and concluded that they "demonstrated remarkable catalytic performance and stability" [139]. A schematic of the immobilization of lipase onto nanoporous gold is shown in Figure 9 [139].

Nanoporous gold has already been shown to be a good support for the immobilization of a wide variety of proteins/enzymes including laccase $[106,108,134,138]$, glucose 


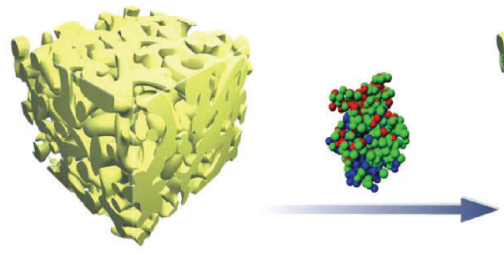

(a)

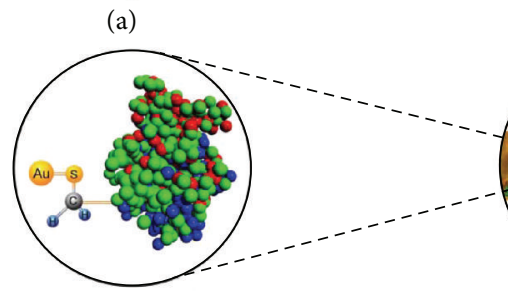

(d)

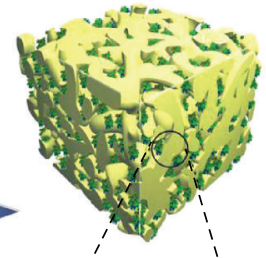

(b)

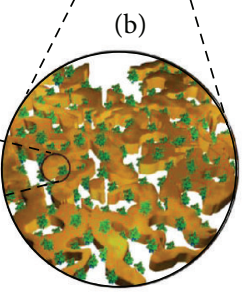

(c)
FIgURE 9: A schematic of the immobilization of lipase onto nanoporous gold [139]. Reprinted from [139].

oxidase [134, 140, 141], alcohol dehydrogenase [141], xylanase [142], acetylcholine esterase [66], cytochrome $c$ [135], ligin peroxidase [143], lipase [139], catalase [139], horseradish peroxidase [139], bovine serum albumin [90], and immunoglobulin G [90]. Strategies for immobilization have included physical, electrostatic, and covalent attachment.

The physical adsorption of laccase (a copper containing oxidase) on the surface of nanoporous gold and the effect of the pore size (10-20 nm, 40-50 nm, and 90-100 nm) has been described [138]. The authors found that a pore size of $40-$ $50 \mathrm{~nm}$ was the most suited for the immobilization of laccase. When the pore size approaches that of the enzyme $(\sim 7 \mathrm{~nm}$ in this case), mass transport of the enzyme or the substrate to the inner pores of nanoporous gold limited the activity of the enzyme [138]. A larger pore size typically means a smaller surface area, thus reducing the amount of immobilized enzyme. Compared to free enzyme, the thermal stability of laccase was improved through immobilization in nanoporous gold [138]. Hakamada et al. also noted the improved thermal stability of nanoporous gold immobilized laccase versus that in solution [106]. Another interesting finding was that direct electron transfer of laccase immobilized on nanoporous gold was observed, whereas it was not when the enzyme was immobilized on a planar gold sheet [138]. This electrode also showed strong electrocatalytic activity toward oxygen reduction [138].

In a later study, the effect of three immobilization strategies (physical, electrostatic, and covalent) on the loading and reaction kinetics for the laccase-catalyzed oxidation of 2,6dimethoxyphenol has also been studied [108]. The authors showed that physical and covalent immobilization gave similar loadings, whereas the electrostatic immobilization was lower by almost a half. Electrostatic immobilization also resulted in the largest amount of enzyme leached into solution. They also showed that crushing the sample improved the efficiency of laccase as more enzymes were accessible [108].

Collectively, these studies and others have demonstrated the potential that nanoporous gold has for the development of stable biosensors with low detection limits and improved stability. More recently, there have also been several studies on the actual development of nanoporous-gold-based biosensors $[140,141]$. For example, in one of the first reports on this subject, Qiu and coworkers constructed an electrochemical biosensor for glucose or ethanol using either glucose oxidase $(\mathrm{GOD})$ or alcohol dehydrogenase $(\mathrm{ADH})$, respectively, immobilized on nanoporous gold (NPG) (pore size $\sim 40 \mathrm{~nm}$ ) formed by chemically dealloying gold leaf in nitric acid and captured on a glassy carbon electrode (GCE) [141]. Nafion was coated on the enzyme-modified electrodes to hold the enzymes in place. The authors showed that the Nafion/ADHNPG/GCE electrode had a fast response time with millimolar concentrations of ethanol, good sensitivity, and a detection limit of $120 \mu \mathrm{M}$ [141]. For the detection of glucose, the authors showed that the Nafion/GOD-nanoporous gold/glassy carbon electrode had good sensitivity at $\mathrm{mM}$ concentrations and a detection limit of $196 \mu \mathrm{M}$ [141]. In both cases, the response was significantly better at the nanoporous gold electrode compared to that prepared from a gold sheet electrode.

In a more recent study, glucose oxidase was linked to the nanoporous gold with different pore sizes via gold-thiol chemistry and used in the amperometric detection of glucose in solution [140]. Different dealloying times (15 min to $8 \mathrm{hrs}$ ) in concentrated acid were used to generate nanoporous gold with different pore sizes ( $\sim 18 \mathrm{~nm}$ to $50 \mathrm{~nm})$. The silver concentration via EDX ranged from 7 to below 1 at \%. The authors found the sensitivity to be higher when the glucose oxidase was covalently attached versus physically adsorbed. The best response was obtained with nanoporous gold containing $30 \mathrm{~nm}$ pores. A detection limit of $10 \mu \mathrm{M}$ was reported [140]. Mass transport limitations would explain why nanoporous gold with the smallest pore size was not observed to give the highest sensitivity [140].

6.4. Small Molecule Sensing. Nanoporous gold electrodes are also ideal for the sensing of small molecules and ions for a number of reasons. Because these molecules are small, they can more readily enter the nanoporous framework. More importantly, however, because many of these small electroactive molecules have sluggish electron transfer rates and/or adsorb on gold, this new found area is electrochemically useful. As described earlier in this paper, nanoporous gold electrodes do not respond to all redox active molecules equally-"discriminative amplification" takes place [14]. At a traditional, planar electrode, it can be challenging to electrochemically measure many electroactive small molecules because they exhibit slow electron transfer rates. However, nanoporous gold is ideal for these types of analytes. The ability to use an electrode that has an electrochemically useful surface area that is 10-100 times larger than a traditional electrode thus offers much promise. Examples of small molecules that have been studied include dopamine [144], ascorbic acid [144], hydrogen peroxide [143, 145], nitrite [146], cysteine [147], nitrophenol [148, 149], hydrazine [150], and glucose [151].

One of the most highly studied small molecules and one that really demonstrates the uniqueness of nanoporous electrodes is glucose. At a traditional planar electrode, this analyte 
is difficult to be measured and thus, an enzyme (e.g., glucose oxidase) is often incorporated into the electrochemical sensor platform $[152,153]$. Recently, however, the nonenzymatic oxidation of glucose on nanoporous gold has been described in a number of reports [79, 151, 154-157]. In 2008, Yin et al. reported on the oxidation of glucose on nanoporous gold with different ligament sizes $(6-250 \mathrm{~nm})$ and also studied the effect of residual silver (6.8 to $37.9 \%$ ) [154]. In this experiment, the nanoporous gold material was crushed and then added to buffer solution along with glucose and a constant supply of oxygen gas. Samples were analyzed via HPLC to determine catalytic activity. Six $\mathrm{nm}$ nanoporous gold, showed more catalytic activity than the $30 \mathrm{~nm}$ nanoporous gold, whereas for the $250 \mathrm{~nm}$ nanoporous gold sample, almost no activity was observed [154]. The authors also noted that "the residual $\mathrm{Ag}$ atoms in the ligaments do not contribute to the observed activity..." [154]. In a study that followed, Liu et al. also examined the electrochemical oxidation of glucose at bare nanoporous gold electrodes with different $\mathrm{Ag}$ composition as well as nanoporous gold containing a monolayer of Ag prepared via underpotential deposition (UPD) [155]. The Ag concentration was determined via EDX. For the electrochemical oxidation of glucose, silver was found to have an important positive effect on the catalytic activity. Compared to bulk gold or nearly pure nanoporous gold, higher catalytic activity for glucose oxidation in alkaline solutions was observed for nanoporous gold that contained $\mathrm{Ag}$ [155]. More recent work has focused on the electroactivity of nanoporous gold electrodes in phosphate buffer solutions and in the presence of chloride ions, ascorbic acid, and uric acid [79] as well as in different solution conditions [151]. Again, it was noted that glucose oxidation was dependent on pore size $(50 \mathrm{~nm}-18 \mathrm{~nm})$, with smaller pore size $(18 \mathrm{~nm})$ providing the highest sensitivity $[79,151]$. Again, this is consistent with the higher amount of Ag present in the sample with the smallest pore/ligament size. Using a potential of $0.3 \mathrm{~V}$, the amperometric detection of glucose was established and a detection limit of $3 \mu \mathrm{M}$ was reported [79]. Using rotating disk voltammetry, Li et al. reported a detection limit of $413 \mathrm{nM}$ [151].

In addition to glucose, other biologically relevant analytes have also been studied. The electrochemistry of dopamine and ascorbic acid has been studied at nanoporous gold electrodes [144]. In this study, the gold leaf was chemically dealloyed and captured on a glassy carbon electrode. Both dopamine and ascorbic acid showed strong electrochemical signals on nanoporous gold. Compared to planar gold, the electrochemical signal was $\sim 2.5 \mathrm{x}$ larger for ascorbic acid and $\sim 6 \mathrm{x}$ larger for dopamine [144]. This difference in enhancement likely reflects difference in the electrochemically accessible electrode areas available to each redox species. In the case of dopamine, it was also found to adsorb on the electrode surface. The determination of dopamine in the presence of ascorbic acid was undertaken using differential pulse voltammetry with a reported detection limit of $17 \mathrm{nM}$ [144].

The amperometric response of nanoporous gold electrodes to NADH and hydrogen peroxide compared to planar gold has been examined [141]. For the oxidation of NADH, the authors report a linear range of 0.02 to $1 \mathrm{mM}$ and a detection limit of $9.5 \mu \mathrm{M}$ and state that it is better than that observed at the planar electrode. The stability of the amperometric response was also significantly better at the nanoporous gold versus planar gold. For $\mathrm{H}_{2} \mathrm{O}_{2}$, nanoporous gold showed a good response for oxidation and reduction while planar gold showed little to no response [141]. In another report, hydrogen peroxide was detected at a nanoporous gold electrode $(\sim 30 \mathrm{~nm}$ pore size; roughness factor of $\sim 8$ ) affixed to a glassy carbon electrode using Nafion as a glue [145]. The authors report a linear range from $10 \mu \mathrm{m}$ to $8 \mathrm{mM}$ and a detection limit of $3.26 \mu \mathrm{M}$ for the amperometric detection of $\mathrm{H}_{2} \mathrm{O}_{2}$ in buffer [145].

The electrocatalytic oxidation of $\mathrm{NO}_{2}{ }^{-}$at glassy carbon, planar gold, and nanoporous gold fixed to glassy carbon with Nafion was reported [146]. A significant electrochemical response (more than 10x) was observed at the nanoporous gold electrode compared to either glassy carbon or a flat gold electrode. The oxidation of $\mathrm{NO}_{2}{ }^{-}$was shown to be a surface-confined redox process. The amperometric detection of $\mathrm{NO}_{2}{ }^{-}$yielded a detection limit of $1 \mu \mathrm{M}$ [146]. Nanoporous gold fixed onto a glassy carbon electrode with Nafion was also used in the electrochemical detection of hydrazine [150]. The oxidation of hydrazine on nanoporous gold, bulk gold, and bare glassy carbon was made. Using amperometry and a rotating disk electrode, the authors report that the steadystate current for the oxidation of hydrazine was proportional to concentration and the detection limit using this method was $16.7 \mathrm{nM}$ [150]. More recently, the oxidation of L-cysteine has been studied on both flat gold and nanoporous gold supported on glassy carbon [147]. Again, the authors note that the overpotential for cysteine oxidation is reduced and the oxidation peak current is much higher compared to that observed at a planar gold electrode. The amperometric detection of cysteine yielded a limit of quantification of $50 \mathrm{nM}$ [147].

The electrochemical detection of nitrophenol using a nanoporous gold electrode has also been reported $[148,149]$. Different electrochemical behavior has been observed on nanoporous gold versus planar gold particularly as it pertains to the different isomers of nitrophenol. An interesting aspect of these studies is that p-nitrophenol can be detected even in the presence of ortho- and metaisomers $[148,149]$. A detection limit of $0.02 \mathrm{mg} / \mathrm{dm}^{3}$ was reported at an unsupported nanoporous gold electrode [148].

6.5. Raman Sensors. Nanoporous gold has been shown to be an excellent substrate for surface-enhanced resonance Raman scattering (SERS) [104, 114, 158-161]. Normally, Raman scattering is very weak but when it is near a suitable surface particularly at "hot" spots, very large enhancements take place. Nanoporous gold with its unique nanostructure that includes small pores, surface irregularities, and small gaps is an ideal surface for surface-enhanced Raman. A number of groups have studied the SERS enhancement as a function of pore size $[104,158,160,162]$. As noted earlier, pore size can be changed in a number of ways including thermal treatment and by electroless growth of gold into the nanoporous 
structure. Superior SERS enhancements have been observed for nanoporous gold with small pore sizes. Qian et al. noted that the strongest SERS enhancement was obtained for nanoporous gold with a pore size of $\sim 5 \mathrm{~nm}$ [160]. They achieved a detection limit that is $\sim 5 \times 10^{-10} \mathrm{M}$ for rhodamine $6 \mathrm{G}$ and indicated that this is about 1-2 orders of magnitude better than that shown on flat planar gold [160]. In another study, a detection limit for rhodamine $6 \mathrm{G}$ and crystal violet of $10^{-10}$ and $10^{-8} \mathrm{M}$, respectively, was reported for nanoporous gold with $\sim 7 \mathrm{~nm}$ pore sizes [104]. One point of concern is that smaller pore sizes often have a larger amount of residual Ag, which is also a good SERS substrate. Recently, the importance of residual Ag on the SERS response has been studied. In this work, the \%Ag was changed by changing the dealloying time and the pore size tailored by thermal annealing [114]. By doing this, the authors were able to prepare nanoporous gold with different Ag concentrations but nearly identical ligament and pore sizes. They concluded that residual Ag contributes to the SERS enhancement of nanoporous gold and that more residual Ag results in a stronger SERS intensity [114].

In a more recent work, attempts to increase SERS enhancements even more have been described. For example, nanoporous gold has been decorated with gold nanoparticles to partially fill in the pores [163]. The authors noted that the enhancement factor of hot spots in the films was significantly larger at a gold-nanoparticle decorated nanoporous gold substrate compared to nanoporous gold without modification [163]. For 4-mercaptopyridine, a detection limit near $10^{-11} \mathrm{M}$ was reported [163]. In another interesting study by Zhang and coworkers, SERSs at wrinkled nanoporous gold films prepared by the thermal contraction of a polymer surface onto which nanoporous gold sits were reported [162]. When the polymer was heated to a temperature above its glass transition point, it shrank and led to the formation of a wrinkled nanoporous gold film. The authors report a $100 \mathrm{x}$ improvement in SERS enhancement on wrinkled nanoporous gold relative to conventional nanoporous gold [162].

6.6. Other Nanoporous Gold Sensors. There are a number of other reports on electrochemical sensors containing "nanoporous gold" that has been made using procedures other than dealloying. A few of these studies will be briefly described herein.

A simple way to make a nanoporous gold-like structure is to just roughen/etch a planar gold electrode using a repetitive square-wave oxidation reduction cycle and/or via application of large potentials for a given period of time [24, 157, 164172]. One example of an electrode made via an anodizing procedure had an area 9.9 times greater than planar gold and was used to make a DNA sensor for detection of the PML/RAR $\alpha$ fusion gene [165]. Other examples of electrodes include those used for the electrochemical detection of hydrogen peroxide (roughness factor of 57.4) [169], thrombin detection (roughness factor of 34) [170], and detection of osteosarcoma-related gene (roughness factor of 42.5) [168]. An example of nanoporous gold prepared using a modified version of this procedure had a roughness factor over 200 and was used in the electrocatalytic oxidation of glucose with promising results [157].

Another method used to prepare what has also been termed nanoporous gold with very high surface areas has been reported. This fabrication process involves the electrochemical formation of $\mathrm{Au}-\mathrm{Zn}$ alloys on a gold electrode immersed in a $\mathrm{ZnCl}_{2}$ and 1-ethyl-3-methylimidazolium ionic liquid $\left(\mathrm{ZnCl}_{2}\right.$-EMIC) at elevated temperatures followed by anodically stripping the alloy [68]. The morphology of the nanoporous gold electrode depends on the $\mathrm{Au}-\mathrm{Zn}$ composition. Ligament sizes ranging from $10 \mathrm{~nm}-60 \mathrm{~nm}$ have been reported as have surface areas that are 200x greater than a planar gold substrate [68]. In a related method, the electrochemical alloying/dealloying process took placed on gold electrodes placed in an electrolyte prepared using $\mathrm{ZnCl}_{2}$ and benzyl alcohol (BA) at elevated temperatures [173]. Figure 10 shows an SEM image of nanoporous gold fabricated by alloying/dealloying in the $\mathrm{ZnCl}_{2} / \mathrm{BA}$ at $120^{\circ} \mathrm{C}$ [173]. An electrode area that was $560 \mathrm{x}$ greater than planar gold was reported [173].

By starting with a $50 \mu \mathrm{m}$ gold wire, nanoporous gold microelectrodes with roughness factors of 100-150 have recently been prepared in a similar fashion [175]. An electrolyte of $\mathrm{ZnCl}_{2}$ and $\mathrm{SnCl}_{2}$ dissolved in benzyl alcohol was used to prepare nanoporous gold with an enormously high surface area: 1250x larger than planar gold, though $\sim 4.12$ atom $\% \mathrm{Zn}$ and 1.59 at \% Sn remained in the nanoporous gold framework [176].

These materials have several important features that include the following: (1) no residual silver is present (but residual $\mathrm{Zn}$ remains (6-20 at \%)) [173, 175]; (2) it does not involve corrosive/dangerous chemicals (e.g., concentrated nitric acids and Au and Ag cyanide salts); and (3) ultrahigh surface areas-higher than those obtained by dealloying gold leaf. Electrodes with surface areas of 200-1250 times larger than planar gold have been reported [68]. Nanoporous gold prepared in this manner has been used in a number of studies including the detection of $\mathrm{Cu}^{2+}$ after surface modification of gold by cysteine [68] or 3-mercaptopropyl sulfonate [177], detection of dopamine with a detection limit of $1 \mathrm{nM}$ [68], detection of hydrogen peroxide after modification with Prussian blue (detection limit of $2 \mu \mathrm{M}$ reported) [178], and the detection of chloride ions after UPD of an adlayer of Ag with a detection limit of $0.5 \mu \mathrm{M}$ [179].

A hydrothermal method has also been used to form nanoporous gold on an etched Ti substrate. In this method, a fairly high concentration of $\mathrm{HAuCl}_{4}$ was mixed with a reducing agent (e.g., ammonium formate, formaldehyde, and polyethylene glycol) and heated in an autoclave at $180^{\circ} \mathrm{C}$ for $8-10 \mathrm{hr}$. The Au-coated substrates were then annealed at $200-250^{\circ} \mathrm{C}$ under argon for several hours [174, 180-182]. The structure of these materials is a bit different than those formed by dealloying consisting of an aggregate network of gold nanoparticles that range in size of 50-500 nm forming pores/openings that are 10 s to 100 s of nanometers in size. The one advantage these materials have is that they do not have any residual silver, but $\mathrm{Ti}$ is present. Figure 11 shows an SEM and its corresponding EDX of nanoporous gold formed in this manner [174]. These materials have been used 

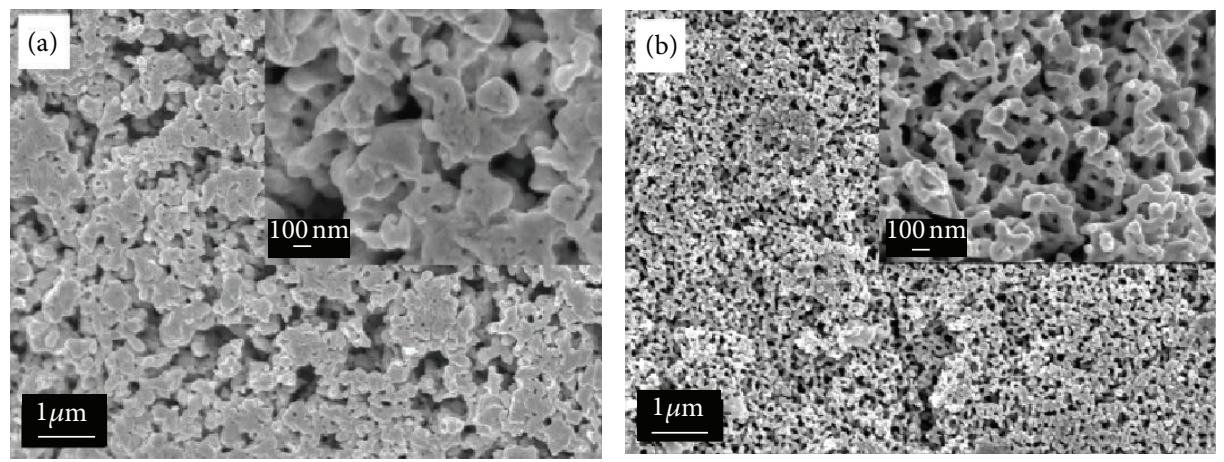

FIGURE 10: Field-emission SEM images of nanoporous gold. (a) 10 cycles at $120^{\circ} \mathrm{C}$, (b) 30 cycles at $120^{\circ} \mathrm{C}$ [173]. Reprinted with permission from [173].

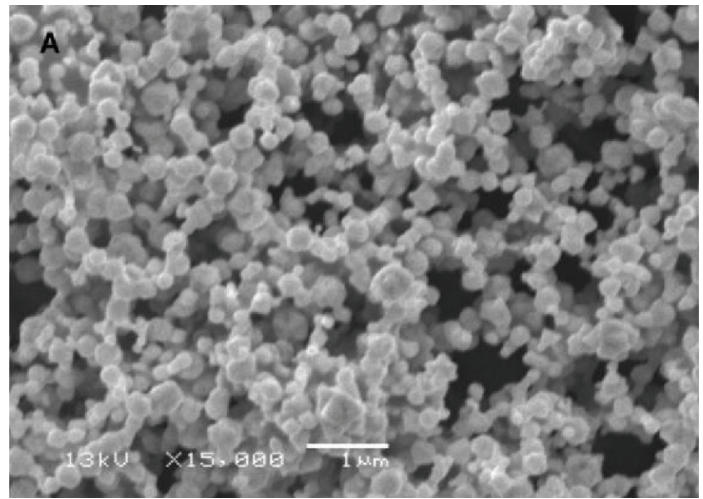

(a)

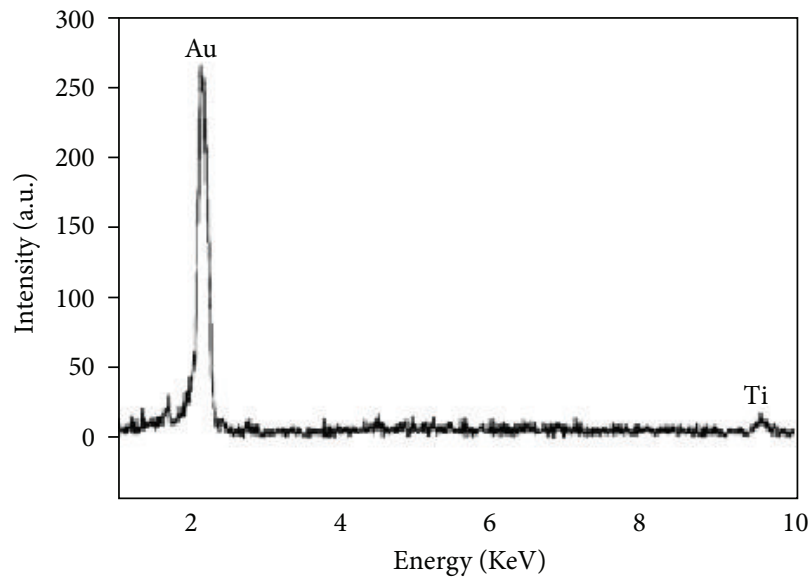

(b)

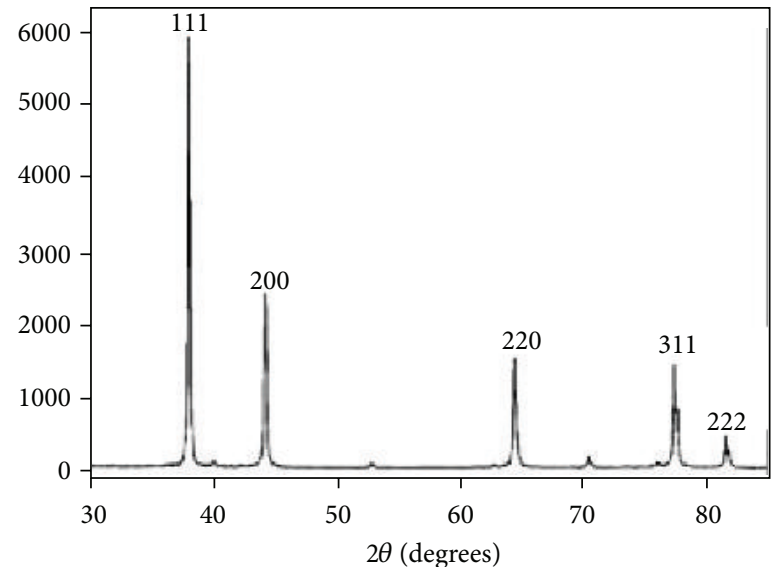

(c)

FIGURE 11: SEM of nanoporous gold formed from a hydrothermal method (a) along with EDX analysis (b) and X-ray diffraction (c) [174]. Reprinted with permission from [174].

as a nonenzymatic sensor to detect glucose with a reported detection limit of $14.8 \mu \mathrm{M}$ [181], glucose-oxidase-based sensor to detect glucose with a reported detection limit of $2.5 \mu \mathrm{M}$ [180], horseradish-peroxidase-immobilized sensor to detect hydrogen peroxide (detection limit of $2 \times 10^{-8} \mathrm{M}$ ) [182], and in the detection of cholesterol [174]. A roughness factor of 5.9 [174] and 19 [181] has been reported.

\section{Conclusions}

Nanoporous gold prepared by dealloying a binary Au:Ag alloy is a promising material for the development of chemical sensors. One of the major reasons it has become so popular in recent years is that it can be easily, quickly, and reproducibly made from readily available sources (e.g., white gold leaf). 
The features that make this material unique are its high surface area, open pore network that can be easily tailored and/or modified, and excellent conductivity making it perfect for sensitive electrochemical detection methods. Recent work in this field has clearly showed the potential for nanoporous gold to impact that field of analytical chemistry. While the trend in materials research seems to be to make materials with higher and higher surface areas, there comes a point, particularly in chemical sensor development, where bigger is not always better. Mass transport limitations will ultimately become important. Through continued advances in the basic science associated with nanoporous metal fabrication and characterization coupled with novel advances in sensing platforms and mechanisms, the future will likely see even more sensitive and selective tools for chemical sensing being developed.

\section{Acknowledgment}

The support from the Virginia Commonwealth University Presidential Research Incentive Fund (PRIP) for the author's work on nanoporous gold is gratefully acknowledged.

\section{References}

[1] F. Schröper, D. Brüggemann, Y. Mourzina, B. Wolfrum, A. Offenhäusser, and D. Mayer, "Analyzing the electroactive surface of gold nanopillars by electrochemical methods for electrode miniaturization," Electrochimica Acta, vol. 53, no. 21, pp. 6265-6272, 2008.

[2] C. Shin, W. Shin, and H. G. Hong, "Electrochemical fabrication and electrocatalytic characteristics studies of gold nanopillar array electrode (AuNPE) for development of a novel electrochemical sensor," Electrochimica Acta, vol. 53, no. 2, pp. $720-$ $728,2007$.

[3] S. J. H. Fathima, J. Paul, and S. Valiyaveettil, "Surface-structured gold-nanotube mats: fabrication, characterization, and application in surface-enhanced Raman scattering," Small, vol. 6, no. 21, pp. 2443-2447, 2010.

[4] S. Marx, M. V. Jose, J. D. Andersen, and A. J. Russell, "Electrospun gold nanofiber electrodes for biosensors," Biosensors \& Bioelectronics, vol. 26, no. 6, pp. 2981-2986, 2011.

[5] M. Kim, G. H. Jeong, K. Y. Lee, K. Kwon, and S. W. Han, "Fabrication of nanoporous superstructures through hierarchical selfassembly of nanoparticles," Journal of Materials Chemistry, vol. 18, no. 19, pp. 2208-2212, 2008.

[6] K. Murata, K. Kajiya, M. Nukaga et al., "A simple fabrication method for three-dimensional gold nanoparticle electrodes and their application to the study of the direct electrochemistry of cytochrome C", Electroanalysis, vol. 22, no. 2, pp. 185-190, 2010.

[7] B. Zhao and M. M. Collinson, "Hierarchical porous gold electrodes: preparation, characterization, and electrochemical behavior," Journal of Electroanalytical Chemistry, vol. 684, pp. 53-59, 2012.

[8] P. N. Bartlett, J. J. Baumberg, P. R. Birkin, M. A. Ghanem, and M. C. Netti, "Highly ordered macroporous gold and platinum films formed by electrochemical deposition through templates assembled from submicron diameter monodisperse polystyrene spheres," Chemistry of Materials, vol. 14, no. 5, pp. 2199-2208, 2002.
[9] Y. Ding, Y. J. Kim, and J. Erlebacher, "Nanoporous gold leaf: "ancient technology"/advanced material," Advanced Materials, vol. 16, no. 21, pp. 1897-1900, 2004.

[10] A. S. Aricò, P. Bruce, B. Scrosati, J. M. Tarascon, and W. Van Schalkwijk, "Nanostructured materials for advanced energy conversion and storage devices," Nature Materials, vol. 4, no. 5, pp. 366-377, 2005.

[11] T. Asefa, C. T. Duncan, and K. K. Sharma, "Recent advances in nanostructured chemosensors and biosensors," Analyst, vol. 134, no. 10, pp. 1980-1990, 2009.

[12] Z. H. Dai and H. X. Ju, "Bioanalysis based on nanoporous materials," Trends in Analytical Chemistry, vol. 39, pp. 149-162, 2012.

[13] N. Menzel, E. Ortel, R. Kraehnert, and P. Strasser, "Electrocatalysis using porous nanostructured materials," Chemphyschem, vol. 13, pp. 1385-1394, 2012.

[14] S. Park, H. C. Kim, and T. D. Chung, "Electrochemical analysis based on nanoporous structures," Analyst, vol. 137, no. 17, pp. 3891-3903, 2012.

[15] E. Seker, M. L. Reed, and M. R. Begley, "Nanoporous gold: fabrication, characterization, and applications," Materials, vol. 2, no. 4, pp. 2188-2215, 2009.

[16] A. Walcarius and A. Kuhn, "Ordered porous thin films in electrochemical analysis," Trends in Analytical Chemistry, vol. 27, no. 7, pp. 593-603, 2008.

[17] A. Wittstock, J. Biener, and M. Bäumer, "Nanoporous gold: a new material for catalytic and sensor applications," Physical Chemistry Chemical Physics, vol. 12, no. 40, pp. 12919-12930, 2010.

[18] Y. Yamauchi and K. Kuroda, "Rational design of mesoporous metals and related nanomaterials by a soft-template approach," Chemistry, vol. 3, no. 4, pp. 664-676, 2008.

[19] P. N. Bartlett, P. R. Birkin, and M. A. Ghanem, "Electrochemical deposition of macroporous platinum, palladium and cobalt films using polystyrene latex sphere templates," Chemical Communications, no. 17, pp. 1671-1672, 2000.

[20] J. Wijnhoven, S. J. M. Zevenhuizen, M. A. Hendriks, D. Vanmaekelbergh, J. J. Kelly, and W. L. Vos, "Electrochemical assembly of ordered macropores in gold," Advanced Materials, vol. 12, no. 12, pp. 888-890, 2000.

[21] F. L. Jia, C. F. Yu, K. J. Deng, and L. Z. Zhang, "Nanoporous metal $(\mathrm{Cu}, \mathrm{Ag}, \mathrm{Au})$ films with high surface area: General fabrication and preliminary electrochemical performance," Journal of Physical Chemistry C, vol. 111, no. 24, pp. 8424-8431, 2007.

[22] K. Sieradzki, N. Dimitrov, D. Movrin, C. McCall, N. Vasiljevic, and J. Erlebacher, "The dealloying critical potential," Journal of the Electrochemical Society, vol. 149, no. 8, pp. B370-B377, 2002.

[23] K. Wagner, S. R. Brankovic, N. Dimitrov, and K. Sieradzki, "Dealloying below the critical potential," Journal of the Electrochemical Society, vol. 144, no. 10, pp. 3545-3555, 1997.

[24] W. Huang, M. Wang, J. Zheng, and Z. Li, "Facile fabrication of multifunctional three-dimensional hierarchical porous gold films via surface rebuilding," Journal of Physical Chemistry C, vol. 113, no. 5, pp. 1800-1805, 2009.

[25] S. J. Guo, S. J. Dong, and E. K. Wang, "Monodisperse raspberrylike gold submicrometer spheres: large-scale synthesis and interface assembling for colloid sphere array," Crystal Growth \& Design, vol. 8, no. 10, pp. 3581-3585, 2008.

[26] Z. H. Li, V. Ravaine, S. Ravaine, P. Garrigue, and A. Kuhn, "Raspberry-like gold microspheres: preparation and electrochemical characterization," Advanced Functional Materials, vol. 17, no. 4, pp. 618-622, 2007. 
[27] J. Biener, A. Wittstock, T. F. Baumann, J. Weissmuller, M. Baumer, and A. V. Hamza, "Surface chemistry in nanoscale materials," Materials, vol. 2, no. 4, pp. 2404-2428, 2009.

[28] J. Weissmüller, R. C. Newman, H. J. Jin, A. M. Hodge, and J. W. Kysar, "Nanoporous metals by alloy corrosion: formation and mechanical properties," MRS Bulletin, vol. 34, no. 8, pp. 577586, 2009.

[29] A. Walcarius, "Template-directed porous electrodes in electroanalysis," Analytical and Bioanalytical Chemistry, vol. 396, no. 1, pp. 261-272, 2010.

[30] Y. G. Guo, J. S. Hu, and L. J. Wan, "Nanostructured materials for electrochemical energy conversion and storage devices," Advanced Materials, vol. 20, no. 23, pp. 2878-2887, 2008.

[31] A. Wittstock, J. Biener, J. Erlebacher, and M. Baumer, Nanoporous Gold: From an Ancient Technology to a High-Tech Material, Royal Society of Chemistry, 2012.

[32] G. S. Attard, P. N. Bartlett, N. R. B. Coleman, J. M. Elliott, J. R. Owen, and J. H. Wang, "Mesoporous platinum films from lyotropic liquid crystalline phases," Science, vol. 278, no. 5339, pp. 838-840, 1997.

[33] P. R. Birkin, J. M. Elliott, and Y. E. Watson, "Electrochemical reduction of oxygen on mesoporous platinum microelectrodes," Chemical Communications, no. 17, pp. 1693-1694, 2000.

[34] H. Boo, S. Park, B. Y. Ku et al., "Ionic strength-controlled virtual area of mesoporous platinum electrode," Journal of the American Chemical Society, vol. 126, no. 14, pp. 4524-4525, 2004.

[35] D. H. Nagaraju and V. Lakshminarayanan, "Electrochemically grown mesoporous gold film as high surface area material for electro-oxidation of alcohol in alkaline medium," Journal of Physical Chemistry C, vol. 113, no. 33, pp. 14922-14926, 2009.

[36] D. B. Robinson, C. A. M. Wu, M. D. Ong, B. W. Jacobs, and B. E. Pierson, "Effect of electrolyte and adsorbates on charging rates in mesoporous gold electrodes," Langmuir, vol. 26, no. 9, pp. 6797-6803, 2010.

[37] B. C. Tappan, S. A. Steiner, and E. P. Luther, "Nanoporous metal foams," Angewandte Chemie - International Edition, vol. 49, no. 27, pp. 4544-4565, 2010.

[38] M. C. Dixon, T. A. Daniel, M. Hieda, D. M. Smilgies, M. H. W. Chan, and D. L. Allara, "Preparation, structure, and optical properties of nanoporous gold thin films," Langmuir, vol. 23, no. 5, pp. 2414-2422, 2007.

[39] Y. Ding and M. W. Chen, "Nanoporous metals for catalytic and optical applications," MRS Bulletin, vol. 34, no. 8, pp. 569-576, 2009.

[40] Z. H. Zhang, Y. Wang, Z. Qi, J. K. Lin, and X. F. Bian, "Nanoporous gold ribbons with bimodal channel size distributions by chemical dealloying of al-au alloys," Journal of Physical Chemistry C, vol. 113, no. 4, pp. 1308-1314, 2009.

[41] Z. H. Zhang, Y. Wang, Z. Qi, C. Somsen, X. G. Wang, and C. C. Zhao, "Fabrication and characterization of nanoporous gold composites through chemical dealloying of two phase Al-Au alloys," Journal of Materials Chemistry, vol. 19, no. 33, pp. 60426050, 2009.

[42] Z. H. Zhang, Y. Wang, Z. Qi, W. H. Zhang, J. Y. Qin, and J. Frenzel, "Generalized fabrication of nanoporous metals (Au, $\mathrm{Pd}, \mathrm{Pt}, \mathrm{Ag}$, and $\mathrm{Cu}$ ) through chemical dealloying," Journal of Physical Chemistry C, vol. 113, no. 29, pp. 12629-12636, 2009.

[43] M. Hakamada and M. Mabuchi, "Nanoporous gold prism microassembly through a self-organizing route," Nano Letters, vol. 6, no. 4, pp. 882-885, 2006.
[44] A. Dursun, D. V. Pugh, and S. G. Corcoran, "A steadystate method for determining the dealloying critical potential," Electrochemical and Solid-State Letters, vol. 6, no. 8, pp. B32B34, 2003.

[45] K. Márquez, R. Ortiz, J. W. Schultze, O. P. Márquez, J. Márquez, and G. Staikov, "In situ FTIR monitoring of Ag and Au electrodeposition on glassy carbon and silicon," Electrochimica Acta, vol. 48, no. 6, pp. 711-720, 2003.

[46] B. Bozzini, G. P. De Gaudenzi, and C. Mele, "A SERS investigation of the electrodeposition of Ag-Au alloys from free-cyanide solutions-part II," Journal of Electroanalytical Chemistry, vol. 570, no. 1, pp. 29-34, 2004.

[47] B. Bozzini, G. P. De Gaudenzi, and C. Mele, "A SERS investigation of the electrodeposition of Ag-Au alloys from free-cyanide solutions," Journal of Electroanalytical Chemistry, vol. 563, no. 1, pp. 133-143, 2004.

[48] C. X. Ji, G. Oskam, Y. Ding, J. D. Erlebacher, A. J. Wagner, and P. C. Searson, "Deposition of $\mathrm{Au}_{x} \mathrm{Ag}_{1-x} / \mathrm{Au}_{y} \mathrm{Ag}_{1-y}$ multilayers and multisegment nanowires," Journal of the Electrochemical Society, vol. 150, no. 8, pp. C523-C528, 2003.

[49] W. S. Chae, D. Van Gough, S. K. Ham, D. B. Robinson, and P. V. Braun, "Effect of ordered intermediate porosity on ion transport in hierarchically nanoporous electrodes," Acs Applied Materials \& Interfaces, vol. 4, no. 8, pp. 3973-3979, 2012.

[50] D. A. McCurry, M. Kamundi, M. Fayette, F. Wafula, and N. Dimitrov, "All electrochemical fabrication of a platinized nanoporous Au thin-film catalyst," Acs Applied Materials \& Interfaces, vol. 3, no. 11, pp. 4459-4468, 2011.

[51] S. Sattayasamitsathit, A. M. O’Mahony, X. Y. Xiao et al., "Highly ordered tailored three-dimensional hierarchical nano/microporous gold-carbon architectures," Journal of Materials Chemistry, vol. 22, pp. 11950-11956, 2012.

[52] L. Liu, W. Lee, Z. Huang, R. Scholz, and U. Gösele, "Fabrication and characterization of a flow-through nanoporous gold nanowire/AAO composite membrane," Nanotechnology, vol. 19, no. 33, Article ID 335604, 2008.

[53] C. X. Ji and P. C. Searson, "Fabrication of nanoporous gold nanowires," Applied Physics Letters, vol. 81, no. 23, pp. 44374439, 2002.

[54] C. X. Ji and P. C. Searson, "Synthesis and characterization of nanoporous gold nanowires," Journal of Physical Chemistry B, vol. 107, no. 19, pp. 4494-4499, 2003.

[55] R. Laocharoensuk, S. Sattayasamitsathit, J. Burdick, P. Kanatharana, P. Thavarungkul, and J. Wang, "Shape-tailored porous gold nanowires: from nano barbells to nano step-cones," ACS Nano, vol. 1, no. 5, pp. 403-408, 2007.

[56] S. H. Yoo and S. Park, "Platinum-coated, nanoporous gold nanorod arrays: synthesis and characterization," Advanced Materials, vol. 19, no. 12, pp. 1612-1615, 2007.

[57] X. H. Gu, L. Q. Xu, F. Tian, and Y. Ding, "Au-Ag alloy nanoporous nanotubes," Nano Research, vol. 2, no. 5, pp. 386-393, 2009.

[58] E. Seker, M. L. Reed, and M. R. Begley, "A thermal treatment approach to reduce microscale void formation in blanket nanoporous gold films," Scripta Materialia, vol. 60, no. 6, pp. 435-438, 2009.

[59] M. Kim, W. J. Ha, J. W. Anh, H. S. Kim, S. W. Park, and D. Lee, "Fabrication of nanoporous gold thin films on silicon substrate by multilayer deposition of Au and Ag," Journal of Alloys and Compounds, vol. 484, no. 1-2, pp. 28-32, 2009.

[60] D. Wang and P. Schaaf, "Nanoporous gold nanoparticles," Journal of Materials Chemistry, vol. 22, pp. 5344-5348, 2012. 
[61] X. L. Quan, L. M. Fischer, A. Boisen, and M. Tenje, "Development of nanoporous gold electrodes for electrochemical applications," Microelectronic Engineering, vol. 88, no. 8, pp. 2379-2382, 2011.

[62] M. Kawasaki and M. Iino, "Self-assembly of alkanethiol monolayers on $\mathrm{Ag}-\mathrm{Au}(111)$ alloy surfaces," Journal of Physical Chemistry B, vol. 110, no. 42, pp. 21124-21130, 2006.

[63] E. Seker, Y. Berdichevsky, M. R. Begley, M. L. Reed, K. J. Staley, and M. L. Yarmush, "The fabrication of low-impedance nanoporous gold multiple-electrode arrays for neural electrophysiology studies," Nanotechnology, vol. 21, no. 12, Article ID 125504, 2010.

[64] E. Rouya, S. Cattarin, M. L. Reed, R. G. Kelly, and G. Zangari, "Electrochemical characterization of the surface area of nanoporous gold films," Journal of the Electrochemical Society, vol. 159, no. 4, pp. K97-K102, 2012.

[65] P. N. Ciesielski, A. M. Scott, C. J. Faulkner, B. J. Berron, D. E. Cliffel, and G. K. Jennings, "Functionalized nanoporous gold leaf electrode films for the immobilization of photosystem I," ACS Nano, vol. 2, no. 12, pp. 2465-2472, 2008.

[66] O. V. Shulga, K. Jefferson, A. R. Khan et al., "Preparation and characterization of porous gold and its application as a platform for immobilization of acetylcholine esterase," Chemistry of Materials, vol. 19, no. 16, pp. 3902-3911, 2007.

[67] Y. H. Tan, J. A. Davis, K. Fujikawa, N. V. Ganesh, A. V. Demchenko, and K. J. Stine, "Surface area and pore size characteristics of nanoporous gold subjected to thermal, mechanical, or surface modification studied using gas adsorption isotherms, cyclic voltammetry, thermogravimetric analysis, and scanning electron microscopy," Journal of Materials Chemistry, vol. 22, no. 14, pp. 6733-6745, 2012.

[68] J. F. Huang and I. W. Sun, "Fabrication and surface functionalization of nanoporous gold by electrochemical alloying/dealloying of $\mathrm{Au}-\mathrm{Zn}$ in an ionic liquid, and the selfassembly of L-cysteine monolayers," Advanced Functional Materials, vol. 15, no. 6, pp. 989-994, 2005.

[69] J. Snyder, P. Asanithi, A. B. Dalton, and J. Erlebacher, "Stabilized nanoporous metals by dealloying ternary alloy precursors," Advanced Materials, vol. 20, no. 24, pp. 4883-4886, 2008.

[70] C. X. Xu, R. Y. Wang, M. W. Chen, Y. Zhang, and Y. Ding, "Dealloying to nanoporous $\mathrm{Au} / \mathrm{Pt}$ alloys and their structure sensitive electrocatalytic properties," Physical Chemistry Chemical Physics, vol. 12, no. 1, pp. 239-246, 2010.

[71] X. G. Wang, J. Z. Sun, C. Zhang, T. Y. Kou, and Z. H. Zhang, "On the microstructure, chemical composition, and porosity evolution of nanoporous alloy through successive dealloying of ternary Al-Pd-Au precursor," Journal of Physical Chemistry C, vol. 116, no. 24, pp. 13271-13280, 2012.

[72] X. G. Wang, J. Frenzel, W. M. Wang et al., "Length-scale modulated and electrocatalytic activity enhanced nanoporous gold by doping," Journal of Physical Chemistry C, vol. 115, no. 11, pp. 4456-4465, 2011.

[73] J. L. Xu, C. Zhang, X. G. Wang et al., "Fabrication of bimodal nanoporous bimetallic Pt-Au alloy with excellent electrocatalytic performance towards formic acid oxidation," Green Chemistry, vol. 13, no. 7, pp. 1914-1922, 2011.

[74] E. Detsi, S. Punzhin, J. C. Rao, P. R. Onck, and J. T. M. De Hosson, "Enhanced strain in functional nanoporous gold with a dual microscopic length scale structure," Acs Nano, vol. 6, no. 5, pp. 3734-3744, 2012.
[75] H. J. Jin, X. L. Wang, S. Parida, K. Wang, M. Seo, and J. Weissmüller, "Nanoporous Au-Pt alloys as large strain electrochemical actuators," Nano Letters, vol. 10, no. 1, pp. 187-194, 2010.

[76] M. Kamundi, L. Bromberg, E. Fey, C. Mitchell, M. Fayette, and N. Dimitrov, "Impact of structure and composition on the dealloying of $\mathrm{Au}_{x} \mathrm{Ag}_{(1-x)}$ alloys on the nanoscale," Journal of Physical Chemistry C, vol. 116, no. 26, pp. 14123-14133, 2012.

[77] X. Lu, T. J. Balk, R. Spolenak, and E. Arzt, "Dealloying of $\mathrm{Au}-\mathrm{Ag}$ thin films with a composition gradient: influence on morphology of nanoporous Au," Thin Solid Films, vol. 515, no. 18, pp. 7122-7126, 2007.

[78] X. Lu, E. Bischoff, R. Spolenak, and T. J. Balk, "Investigation of dealloying in Au-Ag thin films by quantitative electron probe microanalysis," Scripta Materialia, vol. 56, no. 7, pp. 557-560, 2007.

[79] L. Y. Chen, X. Y. Lang, T. Fujita, and M. W. Chen, "Nanoporous gold for enzyme-free electrochemical glucose sensors," Scripta Materialia, vol. 65, no. 1, pp. 17-20, 2011.

[80] L. H. Qian and M. W. Chen, "Ultrafine nanoporous gold by lowtemperature dealloying and kinetics of nanopore formation," Applied Physics Letters, vol. 91, no. 8, Article ID 083105, 2007.

[81] R. Li and K. Sieradzki, "Ductile-brittle transition in random porous Au," Physical Review Letters, vol. 68, no. 8, pp. 1168-1171, 1992.

[82] C. McCall, N. Dimitrov, and K. Sieradzki, "Underpotential deposition on alloys," Journal of the Electrochemical Society, vol. 148, no. 6, pp. E290-E293, 2001.

[83] J. Snyder, K. Livi, and J. Erlebacher, "Dealloying silver/gold alloys in neutral silver nitrate solution: porosity evolution, surface composition, and surface oxides," Journal of the Electrochemical Society, vol. 155, no. 8, pp. C464-C473, 2008.

[84] N. A. Senior and R. C. Newman, "Synthesis of tough nanoporous metals by controlled electrolytic dealloying," Nanotechnology, vol. 17, no. 9, pp. 2311-2316, 2006.

[85] J. Erlebacher and K. Sieradzki, "Pattern formation during dealloying," Scripta Materialia, vol. 49, no. 10, pp. 991-996, 2003.

[86] E. Detsi, M. van de Schootbrugge, S. Punzhin, P. R. Onck, and J. T. M. De Hosson, "On tuning the morphology of nanoporous gold," Scripta Materialia, vol. 64, no. 4, pp. 319-322, 2011.

[87] J. Erlebacher, M. J. Aziz, A. Karma, N. Dimitrov, and K. Sieradzki, "Evolution of nanoporosity in dealloying," Nature, vol. 410, no. 6827, pp. 450-453, 2001.

[88] J. Erlebacher, "An atomistic description of dealloying porosity evolution, the critical potential, and rate-limiting behavior," Journal of the Electrochemical Society, vol. 151, no. 10, pp. C614C626, 2004.

[89] S. Parida, D. Kramer, C. A. Volkert, H. Rösner, J. Erlebacher, and J. Weissmüller, "Volume change during the formation of nanoporous gold by dealloying," Physical Review Letters, vol. 97, no. 3, Article ID 035504, 2006.

[90] Y. H. Tan, J. R. Schallom, N. V. Ganesh, K. Fujikawa, A. V. Demchenko, and K. J. Stine, "Characterization of protein immobilization on nanoporous gold using atomic force microscopy and scanning electron microscopy," Nanoscale, vol. 3, no. 8, pp. 3395-3407, 2011.

[91] T. Fujita, L. H. Qian, K. Inoke, J. Erlebacher, and M. W. Chen, "Three-dimensional morphology of nanoporous gold," Applied Physics Letters, vol. 92, no. 25, Article ID 251902, 2008.

[92] H. Rösner, S. Parida, D. Kramer, C. A. Volkert, and J. Weissmüller, "Reconstructing a nanoporous metal in three 
dimensions: an electron tomography study of dealloyed gold leaf," Advanced Engineering Materials, vol. 9, no. 7, pp. 535-541, 2007.

[93] Y. C. K. Chen, Y. S. Chu, J. Yi et al., "Morphological and topological analysis of coarsened nanoporous gold by $\mathrm{x}$-ray nanotomography," Applied Physics Letters, vol. 96, no. 4, Article ID 043122, 2010.

[94] Y. C. K. Chen-Wiegart, S. Wang, Y. S. Chu et al., "Structural evolution of nanoporous gold during thermal coarsening," Acta Materialia, vol. 60, no. 12, pp. 4972-4981, 2012.

[95] A. Wittstock, B. Neumann, A. Schaefer et al., "Nanoporous $\mathrm{Au}$ : an unsupported pure gold catalyst?" Journal of Physical Chemistry C, vol. 113, no. 14, pp. 5593-5600, 2009.

[96] V. Zielasek, B. Jürgens, C. Schulz et al., "Gold catalysts: nanoporous gold foams," Angewandte Chemie - International Edition, vol. 45, no. 48, pp. 8241-8244, 2006.

[97] A. Schaefer, D. Ragazzon, A. Wittstock et al., "Toward controlled modification of nanoporous gold. A detailed surface science study on cleaning and oxidation," Journal of Physical Chemistry C, vol. 116, no. 7, pp. 4564-4571, 2012.

[98] Y. Liu, S. Bliznakov, and N. Dimitrov, "Comprehensive study of the application of a $\mathrm{pb}$ underpotential deposition-assisted method for surface area measurement of metallic nanoporous materials," Journal of Physical Chemistry C, vol. 113, no. 28, pp. 12362-12372, 2009.

[99] E. Detsi, E. De Jong, A. Zinchenko, and Z. Vukovic, "On the specific surface area of nanoporous materials," Acta Materialia, vol. 59, no. 20, pp. 7488-7497, 2011.

[100] S. Park, Y. J. Song, J. H. Han, H. Boo, and T. D. Chung, "Structural and electrochemical features of 3D nanoporous platinum electrodes," Electrochimica Acta, vol. 55, no. 6, pp. 2029-2035, 2010.

[101] R. Szamocki, A. Velichko, C. Holzapfel et al., "Macroporous ultramicroelectrodes for improved electroanalytical measurements," Analytical Chemistry, vol. 79, no. 2, pp. 533-539, 2007.

[102] J. Erlebacher and R. Seshadri, "Hard materials with tunable porosity," MRS Bulletin, vol. 34, no. 8, pp. 561-568, 2009.

[103] M. Hakamada and M. Mabuchi, "Thermal coarsening of nanoporous gold: melting or recrystallization," Journal of Materials Research, vol. 24, no. 2, pp. 301-304, 2009.

[104] X. Y. Lang, L. Y. Chen, P. F. Guan, T. Fujita, and M. W. Chen, "Geometric effect on surface enhanced Raman scattering of nanoporous gold: improving Raman scattering by tailoring ligament and nanopore ratios," Applied Physics Letters, vol. 94, no. 21, Article ID 213109, 2009.

[105] X. Y. Lang, P. F. Guan, T. Fujita, and M. W. Chen, "Tailored nanoporous gold for ultrahigh fluorescence enhancement," Physical Chemistry Chemical Physics, vol. 13, no. 9, pp. 37953799, 2011.

[106] M. Hakamada, M. Takahashi, and M. Mabuchi, "Enhanced thermal stability of laccase immobilized on monolayermodified nanoporous Au," Materials Letters, vol. 66, pp. 4-6, 2012.

[107] B. Pandey, Y. H. Tan, K. Fujikawa, A. V. Demchenko, and K. J. Stine, "Comparative study of the binding of concanavalin A to self-assembled monolayers containing a thiolated alphamannoside on flat gold and on nanoporous gold," Journal of Carbohydrate Chemistry, vol. 31, no. 4-6, pp. 466-503, 2012.

[108] H. Qiu, C. Xu, X. Huang, Y. Ding, Y. Qu, and P. Gao, "Immobilization of laccase on nanoporous gold: comparative studies on the immobilization strategies and the particle size effects," Journal of Physical Chemistry C, vol. 113, no. 6, pp. 2521$2525,2009$.

[109] O. V. Shulga, D. Zhou, A. V. Demchenko, and K. J. Stine, “Detection of free prostate specific antigen (fPSA) on a nanoporous gold platform," Analyst, vol. 133, no. 3, pp. 319-322, 2008.

[110] Y. Chu, B. Seo, and J. Kim, "Electrochemical properties of alkanethiol monolayers adsorbed on nanoporous au surfaces," Bulletin of the Korean Chemical Society, vol. 31, no. 11, pp. 34073410, 2010.

[111] M. Hakamada, M. Takahashi, T. Furukawa et al., "Electrochemical stability of self-assembled monolayers on nanoporous Au," Physical Chemistry Chemical Physics, vol. 13, no. 26, pp. 1227712284, 2011.

[112] L. V. Moskaleva, S. Röhe, A. Wittstock et al., "Silver residues as a possible key to a remarkable oxidative catalytic activity of nanoporous gold," Physical Chemistry Chemical Physics, vol. 13, no. 10, pp. 4529-4539, 2011.

[113] A. Wittstock, A. Wichmann, J. Biener, and M. Baumer, "Nanoporous gold: a new gold catalyst with tunable properties," Faraday Discussions, vol. 152, pp. 87-98, 2011.

[114] L. Zhang, L. Y. Chen, H. W. Liu et al., "Effect of residual silver on surface-enhanced Raman scattering of dealloyed nanoporous gold," Journal of Physical Chemistry C, vol. 115, no. 40, pp. $19583-$ 19587, 2011.

[115] J. Biener, A. Wittstock, M. M. Biener, T. Nowitzki, A. V. Hamza, and M. Baeumer, "Effect of surface chemistry on the stability of gold nanostructures," Langmuir, vol. 26, no. 17, pp. 13736-13740, 2010.

[116] M. M. Biener, J. Biener, A. Wichmann et al., "ALD functionalized nanoporous gold: thermal stability, mechanical properties, and catalytic activity," Nano Letters, vol. 11, no. 8, pp. 3085-3090, 2011.

[117] Y. Sun and T. J. Balk, "A multi-step dealloying method to produce nanoporous gold with no volume change and minimal cracking," Scripta Materialia, vol. 58, no. 9, pp. 727-730, 2008.

[118] G. W. Nyce, J. R. Hayes, A. V. Hamza, and J. H. Satcher, "Synthesis and characterization of hierarchical porous gold materials," Chemistry of Materials, vol. 19, no. 3, pp. 344-346, 2007.

[119] Y. Ding and J. Erlebacher, "Nanoporous metals with controlled multimodal pore size distribution," Journal of the American Chemical Society, vol. 125, no. 26, pp. 7772-7773, 2003.

[120] M. E. Cox and D. C. Dunand, "Bulk gold with hierarchical macro-, micro- and nano-porosity," Materials Science and Engineering A, vol. 528, no. 6, pp. 2401-2406, 2011.

[121] X. M. Li, X. Y. Yang, and S. S. Zhang, "Electrochemical enzyme immunoassay using model labels," Trends in Analytical Chemistry, vol. 27, no. 6, pp. 543-553, 2008.

[122] P. B. Luppa, L. J. Sokoll, and D. W. Chan, "Immunosensorsprinciples and applications to clinical chemistry," Clinica Chimica Acta, vol. 314, no. 1-2, pp. 1-26, 2001.

[123] N. J. Ronkainen, H. B. Halsall, and W. R. Heineman, "Electrochemical biosensors," Chemical Society Reviews, vol. 39, no. 5, pp. 1747-1763, 2010.

[124] C. F. Ding, H. Li, K. C. Hu, and J. M. Lin, "Electrochemical immunoassay of hepatitis B surface antigen by the amplification of gold nanoparticles based on the nanoporous gold electrode," Talanta, vol. 80, no. 3, pp. 1385-1391, 2010.

[125] R. Li, D. Wu, H. Li et al., "Label-free amperometric immunosensor for the detection of human serum chorionic gonadotropin based on nanoporous gold and graphene," Analytical Biochemistry, vol. 414, no. 2, pp. 196-201, 2011. 
[126] B. Y. Zhao, Q. Wei, C. Xu et al., "Label-free electrochemical immunosensor for sensitive detection of kanamycin," Sensors and Actuators B, vol. 155, no. 2, pp. 618-625, 2011.

[127] Q. Wei, Y. F. Zhao, C. X. Xu et al., "Nanoporous gold film based immunosensor for label-free detection of cancer biomarker," Biosensors \& Bioelectronics, vol. 26, no. 8, pp. 3714-3718, 2011.

[128] M. Zhang, S. G. Ge, W. P. Li et al., "Ultrasensitive electrochemiluminescence immunoassay for tumor marker detection using functionalized Ru-silica@nanoporous gold composite as labels," Analyst, vol. 137, no. 3, pp. 680-685, 2012.

[129] S. G. Ge, X. L. Jiao, and D. R. Chen, "Ultrasensitive electrochemical immunosensor for CA 15-3 using thionine-nanoporous gold-graphene as a platform and horseradish peroxidaseencapsulated liposomes as signal amplification," Analyst, vol. 137, pp. 4440-4447, 2012.

[130] K. C. Hu, D. X. Lan, X. M. Li, and S. S. Zhang, "Electrochemical DNA biosensor based on nanoporous gold electrode and multifunctional encoded DNA-Au bio bar codes," Analytical Chemistry, vol. 80, no. 23, pp. 9124-9130, 2008.

[131] K. C. Hu, P. Liu, S. J. Ye, and S. S. Zhang, "Ultrasensitive electrochemical detection of DNA based on PbS nanoparticle tags and nanoporous gold electrode," Biosensors \& Bioelectronics, vol. 24, no. 10, pp. 3113-3119, 2009.

[132] X. F. Hu, R. Y. Wang, Y. Ding, X. L. Zhang, and W. R. Jin, "Electrochemiluminescence of CdTe quantum dots as labels at nanoporous gold leaf electrodes for ultrasensitive DNA analysis," Talanta, vol. 80, no. 5, pp. 1737-1743, 2010.

[133] M. Yan, M. Zhang, S. G. Ge et al., "Ultrasensitive electrochemiluminescence detection of DNA based on nanoporous gold electrode and PdCu@carbon nanocrystal composites as labels," Analyst, vol. 137, pp. 3314-3320, 2012.

[134] M. Hakamada, M. Takahashi, and M. Mabuchi, "Enzyme electrodes stabilized by monolayer-modified nanoporous $\mathrm{Au}$ for biofuel cells," Gold Bulletin, vol. 45, no. 1, pp. 9-15, 2012.

[135] M. D. Scanlon, U. Salaj-Kosla, S. Belochapkine et al., "Characterization of nanoporous gold electrodes for bioelectrochemical applications," Langmuir, vol. 28, no. 4, pp. 2251-2261, 2012.

[136] V. Vamvakaki and N. A. Chaniotakis, "Immobilization of enzymes into nanocavities for the improvement of biosensor stability," Biosensors \& Bioelectronics, vol. 22, no. 11, pp. 26502655, 2007.

[137] S. Sotiropoulou, V. Vamvakaki, and N. A. Chaniotakis, "Stabilization of enzymes in nanoporous materials for biosensor applications," Biosensors \& Bioelectronics, vol. 20, no. 8, pp. 1674-1679, 2005.

[138] H. Qiu, C. Xu, X. Huang, Y. Ding, Y. Qu, and P. Gao, "Adsorption of lacease on the surface of nanoporous gold and the direct electron transfer between them," Journal of Physical Chemistry C, vol. 112, no. 38, pp. 14781-14785, 2008.

[139] X. Wang, X. Y. Liu, X. L. Yan, P. Zhao, Y. Ding, and P. Xu, "Enzyme-nanoporous gold biocomposite: excellent biocatalyst with improved biocatalytic performance and stability," Plos One, vol. 6, no. 9, Article ID e24207, 2011.

[140] L. Y. Chen, T. Fujita, and M. W. Chen, "Biofunctionalized nanoporous gold for electrochemical biosensors," Electrochimica Acta, vol. 67, pp. 1-5, 2012.

[141] H. J. Qiu, L. Y. Xue, G. L. Ji et al., "Enzyme-modified nanoporous gold-based electrochemical biosensors," Biosensors \& Bioelectronics, vol. 24, no. 10, pp. 3014-3018, 2009.

[142] X. L. Yan, X. Wang, P. Zhao, Y. Zhang, P. Xu, and Y. Ding, "Xylanase immobilized nanoporous gold as a highly active and stable biocatalyst," Microporous and Mesoporous Materials, vol. 161, pp. 1-6, 2012.

[143] H. J. Qiu, Y. Li, G. L. Ji et al., "Immobilization of lignin peroxidase on nanoporous gold: enzymatic properties and in situ release of $\mathrm{H}_{2} \mathrm{O}_{2}$ by co-immobilized glucose oxidase," Bioresource Technology, vol. 100, no. 17, pp. 3837-3842, 2009.

[144] H. J. Qiu, G. P. Zhou, G. L. Ji, Y. Zhang, X. R. Huang, and Y. Ding, "A novel nanoporous gold modified electrode for the selective determination of dopamine in the presence of ascorbic acid," Colloids and Surfaces B, vol. 69, no. 1, pp. 105-108, 2009.

[145] F. H. Meng, X. L. Yan, J. G. Liu, J. Gu, and Z. G. Zou, "Nanoporous gold as non-enzymatic sensor for hydrogen peroxide," Electrochimica Acta, vol. 56, no. 12, pp. 4657-4662, 2011.

[146] X. B. Ge, L. Q. Wang, Z. N. Liu, and Y. Ding, "Nanoporous gold leaf for amperometric determination of nitrite," Electroanalysis, vol. 23, no. 2, pp. 381-386, 2011.

[147] Z. N. Liu, H. C. Zhang, S. F. Hou, and H. Y. Ma, "Highly sensitive and selective electrochemical detection of L-cysteine using nanoporous gold," Microchimica Acta, vol. 177, no. 3-4, pp. 427-433, 2012.

[148] Z. N. Liu, H. C. Zhang, H. Y. Ma, and S. F. Hou, "Selective determination of p-nitrophenol based on its unique voltammetric behavior on nanoporous gold," Electroanalysis, vol. 23, no. 12, pp. 2851-2861, 2011.

[149] Z. N. Liu, J. G. Du, C. C. Qiu et al., "Electrochemical sensor for detection of p-nitrophenol based on nanoporous gold," Electrochemistry Communications, vol. 11, no. 7, pp. 1365-1368, 2009.

[150] X. L. Yan, F. H. Meng, S. Z. Cui, J. G. Liu, J. Gu, and Z. G. Zou, "Effective and rapid electrochemical detection of hydrazine by nanoporous gold," Journal of Electroanalytical Chemistry, vol. 661, no. 1, pp. 44-48, 2011.

[151] Q. Li, S. Cui, and X. Yan, "Electrocatalytic oxidation of glucose on nanoporous gold membranes," Journal of Solid State Electrochemistry, vol. 16, no. 3, pp. 1099-1104, 2012.

[152] S. Park, H. Boo, and T. D. Chung, "Electrochemical nonenzymatic glucose sensors," Analytica Chimica Acta, vol. 556, no. 1, pp. 46-57, 2006.

[153] K. E. Toghill and R. G. Compton, "Electrochemical nonenzymatic glucose sensors: a perspective and an evaluation," International Journal of Electrochemical Science, vol. 5, no. 9, pp. 1246-1301, 2010.

[154] H. Yin, C. Zhou, C. Xu, P. Liu, X. Xu, and Y. Ding, "Aerobic oxidation of D-glucose on support-free nanoporoug gold," Journal of Physical Chemistry C, vol. 112, no. 26, pp. 9673-9678, 2008.

[155] Z. N. Liu, L. H. Huang, L. L. Zhang, H. Y. Ma, and Y. Ding, "Electrocatalytic oxidation of d-glucose at nanoporous $\mathrm{Au}$ and Au-Ag alloy electrodes in alkaline aqueous solutions," Electrochimica Acta, vol. 54, no. 28, pp. 7286-7293, 2009.

[156] B. Seo and J. Kim, "Electrooxidation of glucose at nanoporous gold surfaces: structure dependent electrocatalysis and its application to amperometric detection," Electroanalysis, vol. 22, no. 9, pp. 939-945, 2010.

[157] Y. Xia, W. Huang, J. Zheng, Z. Niu, and Z. Li, "Nonenzymatic amperometric response of glucose on a nanoporous gold film electrode fabricated by a rapid and simple electrochemical method," Biosensors \& Bioelectronics, vol. 26, no. 8, pp. 35553561, 2011.

[158] X. Y. Lang, P. F. Guan, L. Zhang, T. Fujita, and M. W. Chen, "Characteristic length and temperature dependence of surface 
enhanced raman scattering of nanoporous gold," Journal of Physical Chemistry C, vol. 113, no. 25, pp. 10956-10961, 2009.

[159] L. H. Qian, A. Inoue, and M. W. Chen, "Large surface enhanced Raman scattering enhancements from fracture surfaces of nanoporous gold," Applied Physics Letters, vol. 92, no. 9, Article ID 093113, 2008.

[160] L. H. Qian, X. Q. Yan, T. Fujita, A. Inoue, and M. W. Chen, "Surface enhanced Raman scattering of nanoporous gold: Smaller pore sizes stronger enhancements," Applied Physics Letters, vol. 90, no. 15, Article ID 153120, 2007.

[161] Y. Jiao, J. D. Ryckman, P. N. Ciesielski, C. A. Escobar, G. K. Jennings, and S. M. Weiss, "Patterned nanoporous gold as an effective SERS template," Nanotechnology, vol. 22, no. 29, Article ID 295302, 2011.

[162] L. Zhang, X. Y. Lang, A. Hirata, and M. W. Chen, "Wrinkled nanoporous gold films with ultrahigh surface-enhanced raman scattering enhancement," ACS Nano, vol. 5, no. 6, pp. 44074413, 2011.

[163] L. H. Qian, B. Das, Y. Li, and Z. L. Yang, "Giant Raman enhancement on nanoporous gold film by conjugating with nanoparticles for single-molecule detection," Journal of Materials Chemistry, vol. 20, no. 33, pp. 6891-6895, 2010.

[164] Y. Deng, W. Huang, X. Chen, and Z. Li, "Facile fabrication of nanoporous gold film electrodes," Electrochemistry Communications, vol. 10, no. 5, pp. 810-813, 2008.

[165] G. Zhong, A. Liu, X. Chen et al., "Electrochemical biosensor based on nanoporous gold electrode for detection of PML/RAR $\alpha$ fusion gene," Biosensors \& Bioelectronics, vol. 26, no. 9, pp. 3812-3817, 2011.

[166] H. Qiu and X. Huang, "Effects of Pt decoration on the electrocatalytic activity of nanoporous gold electrode toward glucose and its potential application for constructing a nonenzymatic glucose sensor," Journal of Electroanalytical Chemistry, vol. 643, no. 1-2, pp. 39-45, 2010.

[167] L. E. Ahangar and M. A. Mehrgardi, "Nanoporous gold electrode as a platform for the construction of an electrochemical DNA hybridization biosensor," Biosensors \& Bioelectronics, vol. 38, no. 1, pp. 252-257, 2012.

[168] G. Zhong, A. Liu, X. Xu et al., "Detection of femtomolar level osteosarcoma-related gene via a chronocoulometric DNA biosensor based on nanostructure gold electrode," International Journal of Nanomedicine, vol. 7, pp. 527-536, 2012.

[169] M. Zheng, P. Li, C. Yang et al., "Ferric ion immobilized on three-dimensional nanoporous gold films modified with self-assembled monolayers for electrochemical detection of hydrogen peroxide," Analyst, vol. 137, no. 5, pp. 1182-1189, 2012.

[170] H. Qiu, Y. Sun, X. Huang, and Y. Qu, "A sensitive nanoporous gold-based electrochemical aptasensor for thrombin detection," Colloids and Surfaces B, vol. 79, no. 1, pp. 304-308, 2010.

[171] S. Cherevko and C.-H. Chung, "Direct electrodeposition of nanoporous gold with controlled multimodal pore size distribution," Electrochemistry Communications, vol. 13, no. 1, pp. 1619, 2011.

[172] C. Fang, N. M. Bandaru, A. V. Ellis, and N. H. Voelcker, "Electrochemical fabrication of nanoporous gold," Journal of Materials Chemistry, vol. 22, pp. 2952-2957, 2012.

[173] F. Jia, C. Yu, Z. Ai, and L. Zhang, "Fabrication of nanoporous gold film electrodes with ultrahigh surface area and electrochemical activity," Chemistry of Materials, vol. 19, no. 15, pp. 3648-3653, 2007.
[174] A. Ahmadalinezhad and A. C. Chen, "High-performance electrochemical biosensor for the detection of total cholesterol," Biosensors \& Bioelectronics, vol. 26, no. 11, pp. 4508-4513, 2011.

[175] J. Jiang and X. Wang, "Fabrication of high-surface nanoporous gold microelectrode," Electrochemistry Communications, vol. 20, pp. 157-159, 2012.

[176] F. Jia, C. Yu, and L. Zhang, "Hierarchical nanoporous gold film electrode with extra high surface area and electrochemical activity," Electrochemistry Communications, vol. 11, no. 10, pp. 1944-1946, 2009.

[177] J. F. Huang and B. T. Lin, "Application of a nanoporous gold electrode for the sensitive detection of copper via mercuryfree anodic stripping voltammetry," Analyst, vol. 134, no. 11, pp. 2306-2313, 2009.

[178] F. Jia, C. Yu, J. Gong, and L. Zhang, "Deposition of Prussian blue on nanoporous gold film electrode and its electrocatalytic reduction of $\mathrm{H}_{2} \mathrm{O}_{2}$," Journal of Solid State Electrochemistry, vol. 12, no. 12, pp. 1567-1571, 2008.

[179] J.-F. Huang, "Silver UPD ultra-thin film modified nanoporous gold electrode with applications in the electrochemical detection of chloride," Talanta, vol. 77, no. 5, pp. 1694-1700, 2009.

[180] A. Ahmadalinezhad, A. K. M. Kafi, and A. C. Chen, "Glucose biosensing based on the highly efficient immobilization of glucose oxidase on a Prussian blue modified nanostructured $\mathrm{Au}$ surface," Electrochemistry Communications, vol. 11, no. 10, pp. 2048-2051, 2009.

[181] Q. F. Yi and W. Q. Yu, "Electrocatalytic activity of a novel titanium-supported nanoporous gold catalyst for glucose oxidation," Microchimica Acta, vol. 165, no. 3-4, pp. 381-386, 2009.

[182] A. K. M. Kafi, A. Ahmadalinezhad, J. P. Wang, D. F. Thomas, and A. C. Chen, "Direct growth of nanoporous Au and its application in electrochemical biosensing," Biosensors \& Bioelectronics, vol. 25, no. 11, pp. 2458-2463, 2010. 

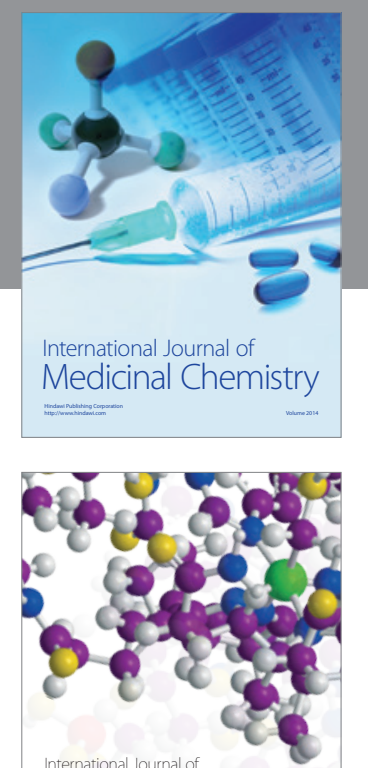

\section{Carbohydrate} Chemistry

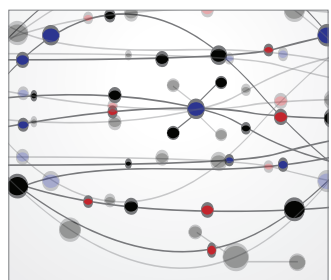

The Scientific World Journal
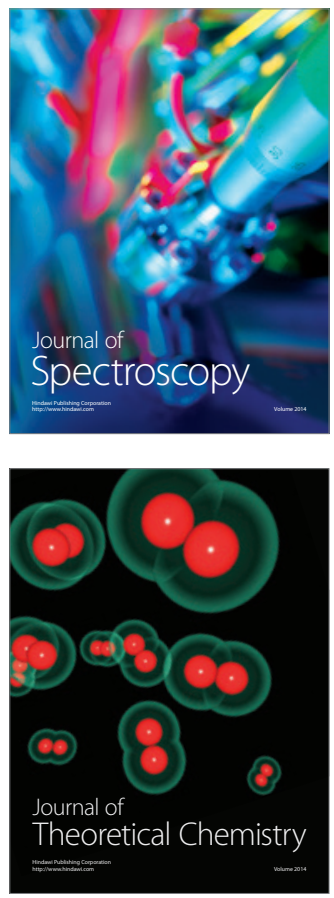
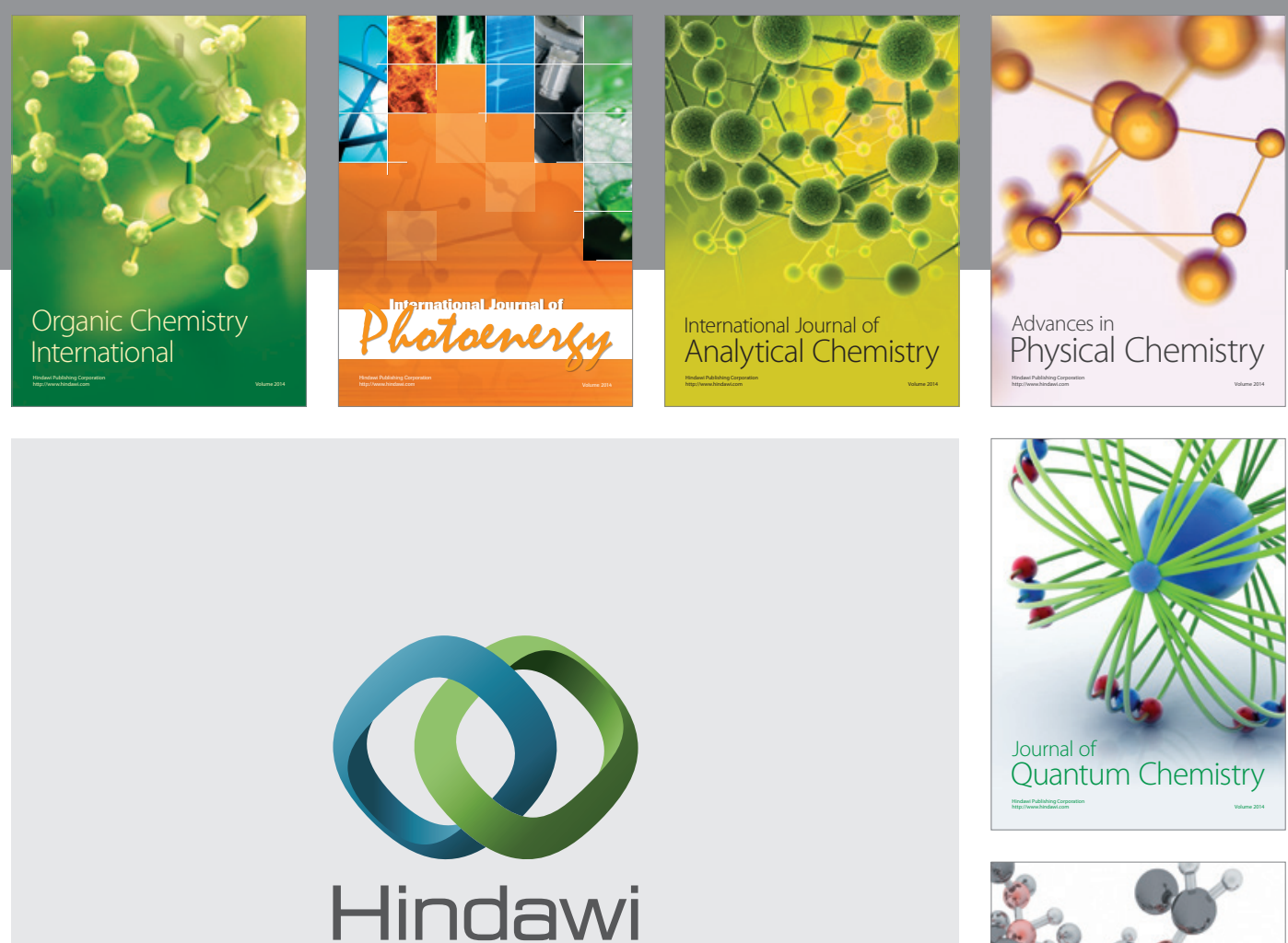

Submit your manuscripts at

http://www.hindawi.com

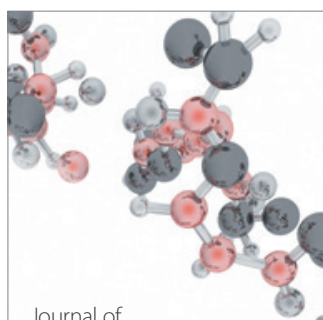

Analytical Methods

in Chemistry

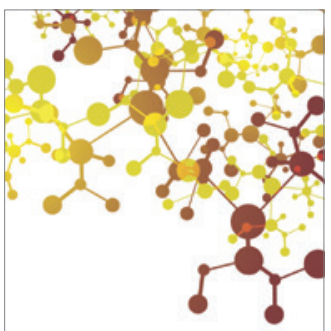

Journal of

Applied Chemistry

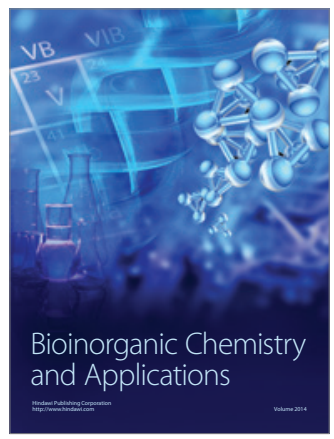

Inorganic Chemistry
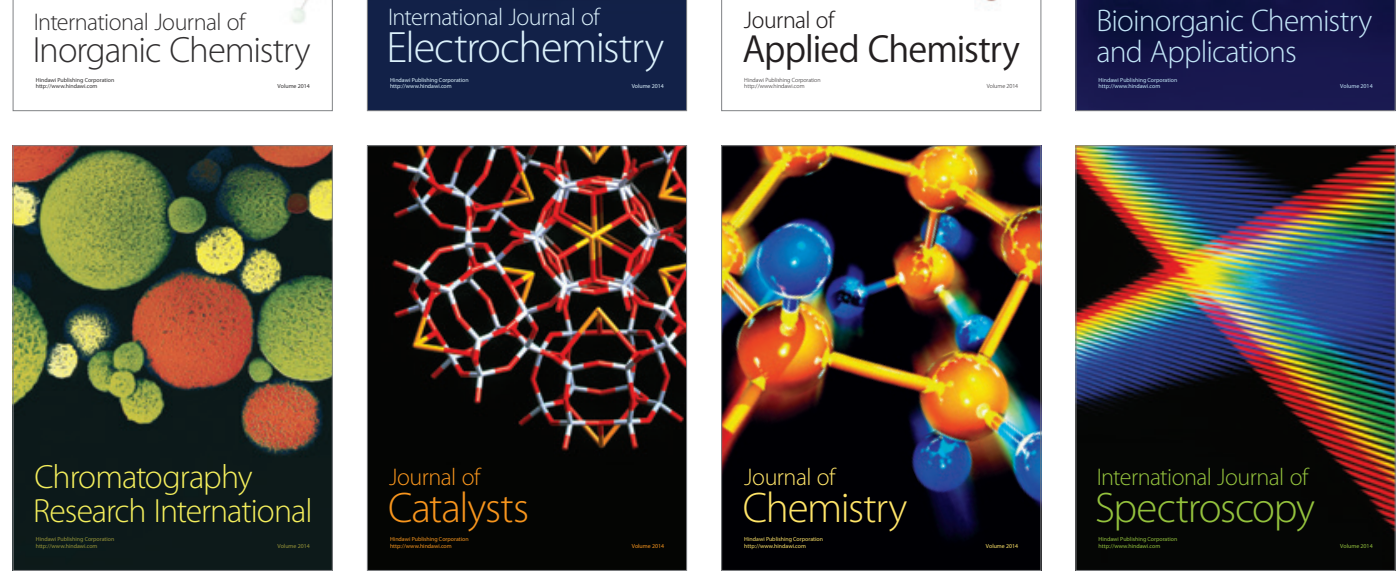